\title{
Review of Machine Learning in Lung Ultrasound in COVID-19 Pandemic
}

\author{
Jing Wang ${ }^{1}{ }^{\mathbb{D}}$, Xiaofeng Yang ${ }^{1}$, Boran Zhou ${ }^{1}$, James J. Sohn ${ }^{2}$, Jun Zhou ${ }^{1}$, Jesse T. Jacob ${ }^{3}$, Kristin A. Higgins ${ }^{1}$, \\ Jeffrey D. Bradley ${ }^{1}$ and Tian Liu ${ }^{1, *}$
}

1 Department of Radiation Oncology, Emory University, Atlanta, GA 30322, USA; jing.wang2@emory.edu (J.W.); xyang43@emory.edu (X.Y.); boran.zhou@emory.edu (B.Z.); jun.zhou@emory.edu (J.Z.); kristin.higgins@emory.edu (K.A.H.); jeffrey.d.bradley@emory.edu (J.D.B.)

2 Department of Radiation Oncology, Virginia Commonwealth University, Richmond, VA 23219, USA; modeljyy@gmail.com

3 Division of Infectious Diseases, Department of Medicine, Emory University, Atlanta, GA 30322, USA; jtjacob@emory.edu

* Correspondence: tliu34@emory.edu; Tel.: +1-(404)-778-1848

check for updates

Citation: Wang, J.; Yang, X.; Zhou, B.; Sohn, J.J.; Zhou, J.; Jacob, J.T.; Higgins, K.A.; Bradley, J.D.; Liu, T. Review of Machine Learning in Lung Ultrasound in COVID-19 Pandemic. J. Imaging 2022, 8, 65. https:// doi.org/10.3390/jimaging8030065

Academic Editor: Aaron Fenster

Received: 12 February 2022

Accepted: 2 March 2022

Published: 5 March 2022

Publisher's Note: MDPI stays neutral with regard to jurisdictional claims in published maps and institutional affiliations.

Copyright: (C) 2022 by the authors. Licensee MDPI, Basel, Switzerland. This article is an open access article distributed under the terms and conditions of the Creative Commons Attribution (CC BY) license (https:// creativecommons.org/licenses/by/ $4.0 /)$.

\begin{abstract}
Ultrasound imaging of the lung has played an important role in managing patients with COVID-19-associated pneumonia and acute respiratory distress syndrome (ARDS). During the COVID-19 pandemic, lung ultrasound (LUS) or point-of-care ultrasound (POCUS) has been a popular diagnostic tool due to its unique imaging capability and logistical advantages over chest X-ray and CT. Pneumonia/ARDS is associated with the sonographic appearances of pleural line irregularities and B-line artefacts, which are caused by interstitial thickening and inflammation, and increase in number with severity. Artificial intelligence (AI), particularly machine learning, is increasingly used as a critical tool that assists clinicians in LUS image reading and COVID-19 decision making. We conducted a systematic review from academic databases (PubMed and Google Scholar) and preprints on arXiv or TechRxiv of the state-of-the-art machine learning technologies for LUS images in COVID19 diagnosis. Openly accessible LUS datasets are listed. Various machine learning architectures have been employed to evaluate LUS and showed high performance. This paper will summarize the current development of AI for COVID-19 management and the outlook for emerging trends of combining AI-based LUS with robotics, telehealth, and other techniques.
\end{abstract}

Keywords: lung ultrasound; machine learning; deep learning; COVID-19; artificial intelligence (AI)

\section{Introduction}

The COVID-19 pandemic has posed an extraordinary challenge to the global public health system due to the high infection and mortality rate [1]. The hallmark of severe COVID-19 is pneumonia and acute respiratory distress syndrome (ARDS) [2-4]. Among symptomatic patients with COVID-19, 14\% are hospitalized, 2\% require intensive care with an overall mortality rate of $5 \%$. Severe illness can occur in healthy individuals but is more frequent among those with common medical morbidities, including increasing age, diabetes and chronic lung, kidney, liver or heart disease, and mortality may be up to 12-fold in these populations [5]. Medical imaging provides an important tool to diagnose COVID-19 pneumonia and reflect the pathological conditions of the lung [6-13]. Lung ultrasound (LUS) or point-of-care ultrasound (POCUS) is an emerging imaging technique that has demonstrated higher diagnostic sensitivity and accuracy than a chest X-ray and is comparable to CT in COVID-19 diagnosis [14]. For simplicity, we will use LUS instead of LUS/POCUS in this paper. LUS has unique advantages of being portable, prompt, repeatable, low cost, easy to use, and free of ionizing radiation $[15,16]$. LUS can be used at all steps to evaluate COVID-19 patients from triage, diagnosis, and follow-up exams. Over two years into the COVID-19 pandemic, the number of daily confirmed COVID-19 cases is still 
striking, and new variants are being identified, requiring efficient diagnostic tools to guide clinical practice in triage and management of potentially suspected populations [17-19]. Figure 1 shows the rapid increases of artificial intelligence (AI) publications for COVID-19 diagnosis with US and all imaging modalities (CT, X-ray, and US) in PubMed database.

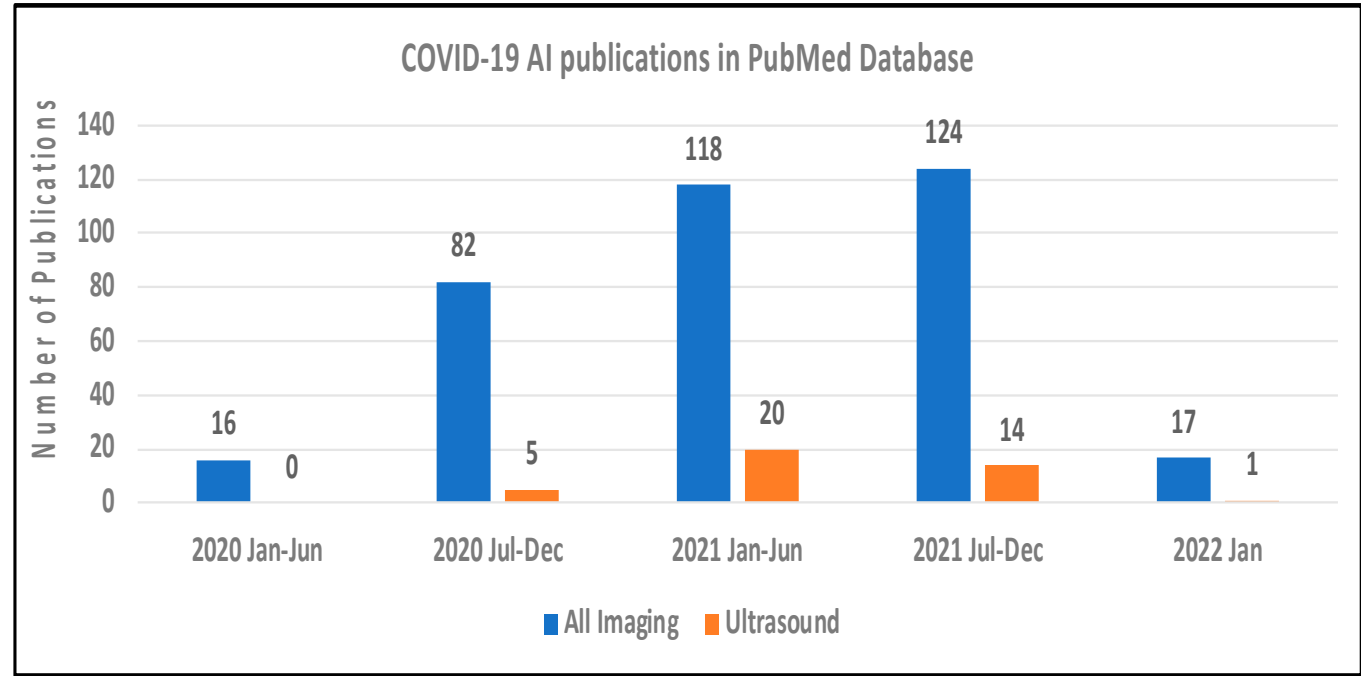

Figure 1. The number of COVID-19 AI publications based on ultrasound (orange bars) and CT, X-ray and ultrasound combined (blue bars) in PubMed Database, as of 17 January 2022.

This review aims to outline current and emerging clinical applications of machine learning (ML) in LUS during the COVID-19 pandemic. We conducted a literature search with keywords including "COVID-19", "AI", "Machine Learning", and "Deep Learning". We first searched the PubMed database with a combination of "COVID-19" AND "ultrasound" AND "AI OR Machine Learning OR Deep Learning OR Auto" in the title and abstract fields. For a more comprehensive literature review, we further searched keywords: "COVID-19" + "Ultrasound" + "AI/Machine Learning/Deep Learning" on Google Scholar. Combining the results from PubMed and Google scholar, we reviewed recent original research articles focusing on ML applications of LUS in COVID-19, consisting of journal articles, conference papers, arXiv or TechRxiv preprints and book chapters. More than 35 research articles were reviewed and summarized in the following sections.

\section{LUS Scan Protocols and Features of COVID-19}

\subsection{LUS Scan Protocols}

A variety of LUS scanning schemes for COVID-19 patients exist. LUS has been performed with US scanners ranging from high-end systems to hand-held devices [20-25] and different transducers, including convex, linear, and phased array transducers [26-29]. Scans have been performed with patients in the sitting, supine or decubitus positions. Several scan methods have been reported, including the BLUE protocol (6-point scans), 10-point scans [30,31], 12-zone scans [32,33], and 14-zone scans [34,35], all aiming to examine the whole lung in a standardized and thorough manner. The intercostal scanning tries to cover more surfaces in a single scan and evaluates the ultrasound patterns bilaterally in multiple regions to evaluate the overall severity of lung diseases. The BLUE (Bedside Lung Ultrasound in Emergency, Figure 2) protocol works in respiratory failure settings [36] and is thus a suitable practice for rapid COVID-19 scans [37]. Three standardized points for scanning at one side of the lung and bilaterally six key zones in total are examined [37,38]. The three BLUE-points include at one side the upper and lower BLUE-point (anterior) and the PLAPS (posterolateral alveolar and/or pleural syndrome) BLUE-point. Such scanning protocols may be followed to acquire at-home LUS [39]. 

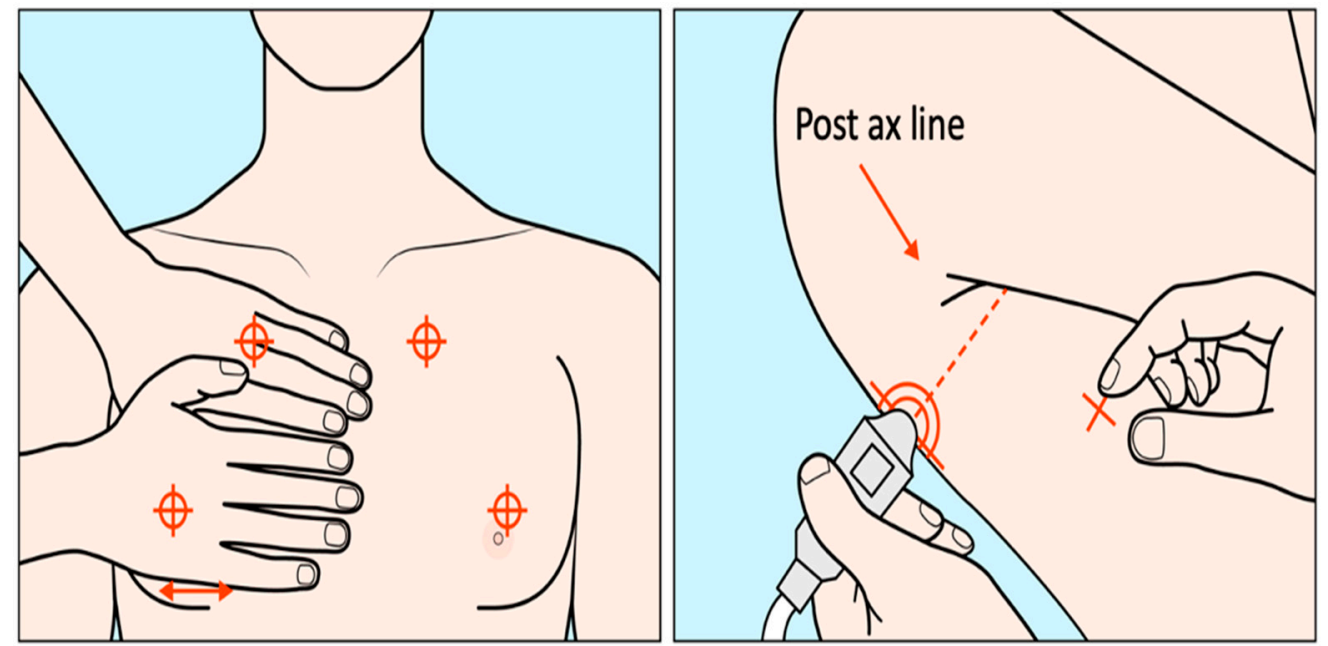

Figure 2. The three standard BLUE points are illustrated (two anterior and one posterior) [modified from [40]]. Two hands are placed on the front chest such that the upper hand touches the clavicle, and the upper anterior BLUE-point is in the middle of the upper hand, while the lower anterior BLUE-point is in the middle of the lower palm. The PLAPS-point is vertically at the posterior axillary line and horizontally at the same level of the lower anterior BLUE-point.

\subsection{LUS Image Features for COVID-19 Pneumonia}

When compared to liquids or soft tissues, the air-filled lung presents significant differences in acoustic properties. As shown in Figure 3, LUS images distinguish a healthy lung from a lung with interstitial pathology mainly via artifacts [41]. For a healthy lung with a normally aerated pleural plane, the incident ultrasound pulses are almost completely reflected by the regular pleural plane, resulting in horizontal linear artifacts parallel to the pleural plane (A-lines). When the ratio of air to fluid in the lung is changed, the lung and pleural tissues lose the regular structure and can no longer function as a complete specular reflector of the incident ultrasound signals, thus producing various artifacts [29]. One important artifact is the B-line, a type of vertical artifact beginning from the plural plane, focal or confluent [20]. B-lines are believed to correlate with the volume of extravascular lung water and interstitial lung diseases, cardiogenic and non-cardiogenic lung edema, interstitial pneumonia, and lung contusion [42]. Overall, COVID-19 pneumonia/ARDS is associated with the sonographic appearances of pleural line irregularities and B-line artefacts, which are caused by interstitial thickening and inflammation, and increase in number with severity.

Many review papers have discussed the LUS image characteristics for COVID-19 pneumonia $[6,14,20,43-47]$. When diagnosing COVID-19, the diffuse B-lines are the most commonly seen in US findings, followed by the pleural line irregularities and subpleural consolidations as the next most frequent findings [20,30,31,39,48,49], while the pleural diffusions appear less often $[20,21,26,30,31,48,50]$. The reappearance of A-lines is expected during the recovery phase or in normal lungs [24,48], and the "white lung" (multi B-lines coalescing) is observed as pneumonia deteriorates [31,45]. 

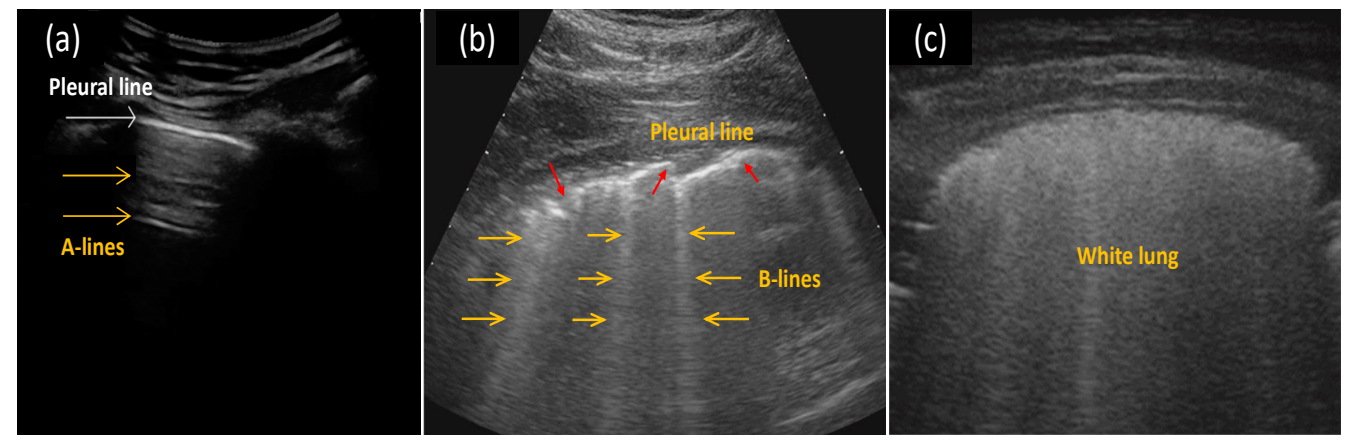

Figure 3. Examples of (a) horizontal A-lines (yellow arrows) in a normal lung, (b) multiple B-lines (yellow arrows) with an irregular pleura line (red arrows) in a COVID-19 indicative lung, and (c) white lung (completely diffused B-lines) for severe COVID-19 pneumonia. Reprinted with permission from ref. [34,51]. Copyright 2020 John Wiley and Sons.

\subsection{LUS Grading Systems of COVID-19 Pneumonia}

Various grading systems have been proposed to classify COVID-19 pneumonia using LUS images (A-lines, B-lines, pleural lines, and subpleural consolidates). For instance, Soldati et al. [35] proposed a scoring scheme that classifies the severity of pneumonia into four stages: score 0 is when a regular pleural line and horizontal A-lines are observed, indicating a normal lung; score 1 is when indented pleural lines and vertical white areas below the indent are observed; score 2 is when the broken pleural lines, small-to-large consolidations and multiple or confluent B-lines are observed (white lung happens at this stage); score 3 is the highest level of severity, where the white lung is dense and extends to large areas. Similar scoring systems were proposed by Volpicelli et al. [52], Deng et al. [53], Lichter et al. [54], and Castelao et al. [50]. Such LUS scores could be utilized in AI algorithms for a future auto-grading system of pathology severity.

\section{Machine Learning in COVID-19 LUS}

\subsection{Public-Accessible Databases}

AI is commonly used in medical imaging for detecting diseases [55]. Machine learning (ML) such as deep learning (DL) are powerful techniques used in AI, and large databases are critically important. Many of the current COVID-19 imaging datasets consist of CTs, such as COVID-CT [56], or based on X-rays, such as COVIDx [57], with only a few containing collections of ultrasound images [58]. Table 1 summarizes publicly accessible LUS databases.

Table 1. Large online open databases of COVID-19 ultrasound images.

\begin{tabular}{|c|c|c|}
\hline Database & Data Characteristics & Access Link \\
\hline POCUS dataset [59] & $\begin{array}{l}64 \text { lung POCUS video recordings, divided into } 39 \text { videos of } \\
\text { COVID-19, } 14 \text { of (typical bacterial) pneumonia and } 11 \text { of } \\
\text { healthy patients. }\end{array}$ & $\begin{array}{l}\text { https:/ / github.com/jannisborn/covid19_pocus__ } \\
\text { ultrasound (29 November 2020) }\end{array}$ \\
\hline $\begin{array}{l}\text { Enlarged POCUS dataset } \\
\qquad[60]\end{array}$ & $\begin{array}{c}139 \text { recordings (106 videos }+33 \text { images) with convex or linear } \\
\text { probes. } \\
63 \text { COVID-19, } 34 \text { bacterial pneumonia, } 7 \text { virial pneumonia } \\
\text { and } 35 \text { healthy cases. }\end{array}$ & $\begin{array}{l}\text { https://github.com/jannisborn/covid19_pocus__ } \\
\text { ultrasound/tree/master/data (29 November 2020) }\end{array}$ \\
\hline New POCUS dataset [61] & $\begin{array}{l}202 \text { videos and } 59 \text { images from } 216 \text { patients. } \\
\text { COVID-19, bacterial pneumonia, non-COVID-19 viral } \\
\text { pneumonia and healthy controls. }\end{array}$ & $\begin{array}{c}\text { https: } \\
\text { / / github.com/BorgwardtLab/covid19_ultrasound } \\
\text { (1 December 2021) }\end{array}$ \\
\hline ICLUS-DB [35] & $\begin{array}{l}30 \text { cases of confirmed COVID-19 for a total of about } 60,000 \\
\text { frames by the time of publishment. }\end{array}$ & $\begin{array}{l}\text { https:/ / covid19.disi.unitn.it/iclusdb } \\
\text { (29 November 2020) }\end{array}$ \\
\hline
\end{tabular}


Table 1. Cont.

\begin{tabular}{cccc}
\hline Database & Data Characteristics & Access Link \\
\hline Extended ICLUS-DB [62] & $\begin{array}{c}\text { An extended and fully annotated version of ICLUS-DB. } \\
\text { 277 LUS videos from 35 patients (17 positive COVID-19, } \\
\text { 4 COVID-19 suspected and 14 healthy patients). }\end{array}$ & $\begin{array}{c}\text { https://iclus-web.bluetensor.ai } \\
\text { (29 November 2020) }\end{array}$ \\
\hline COVIDx-US [63] & $\begin{array}{c}59 \text { COVID-19 videos, 37 non-COVID-19 videos, 41 videos } \\
\text { with other lung diseases/conditions, and 13 videos of } \\
\text { normal patients. }\end{array}$ & $\begin{array}{c}\text { (1 December 2021) } \\
\text { hithub.com/nrc-cnrc/COVID-US }\end{array}$ \\
\hline
\end{tabular}

Born et al. released a lung ultrasound dataset (POCUS) in May 2020. The POCUS dataset had 1103 images sampled from 64 videos, consisting of 654 COVID-19, 277 bacterial pneumonia, and 172 healthy controls [59], which later was enlarged to include 106 videos [60]. In January 2021, Born et al. released an updated version of the dataset, including 202 videos of COVID-19, bacterial pneumonia, non-COVID-19 viral pneumonia patients and healthy controls [61]. In March 2020, Soldati et al. proposed an internationally standardized acquisition protocol and 4-level scoring schemes for LUS in COVID-19 [35]. They shared 30 positive COVID-19 cases in an online database (ICLUS-DB database), containing about 60,000 frames. Roy et al. proposed an extended and fully-annotated version of the previous ICLUS-DB database, which includes a total of 277 LUS videos from 35 patients [62]. The frames from these videos were labeled according to the 4-level scoring system.

More recently, in March 2021, Ebadi et al. presented an open-access LUS benchmark dataset, COVIDx-US, collecting images from multiple sources [63]. The COVIDx-US dataset consists of 150 videos (12943 frames) in total, categorized into four subsets: COVID-19, non-COVID-19, other lung diseases, and healthy patients. Another group worked on a 12-lung-field scanning protocol of thoracic POCUS (T-POCUS) images for COVID-19 patients [64]. The preliminary dataset consists of 16 subjects (mean age 67 years old), with $81 \%$ being male. Their data were stored in the Butterfly IQ cloud, so it might not be openly accessible.

\subsection{Traditional Machine Learning Classifiers}

Several traditional ML algorithms were utilized for LUS image analyses. Principal component analysis (PCA) and independent component analysis (ICA) could extract image features. Random forest, support vector machine (SVM), k-Nearest Neighbour (KNN), decision trees, and logistic regression could perform subsequent classifications [65]. In COVID-19 LUS image analyses, SVM classifiers are commonly used.

\subsubsection{Support Vector Machine (SVM) Classifier}

Carrer et al. trained a support vector machine (SVM) classifier to predict the COVID-19 LUS score on subsets of the ICLUS-DB database [66]. The process mainly focused on the pleural line and areas beneath the line, which was implemented in two major steps. The first step was to identify the pleural line in each frame picked from the LUS videos. A circular averaging filter was used to smooth out the background noise. Then a Rician-based statistical model [67] was employed to enhance the bright areas (plural lines and other tissues) from the dark background. Next, a local scale hidden Markov model (HMM) and the Viterbi algorithm (VA) [68] were adapted to detect all the horizontal linear high-lighted sections. The deepest linear sections with strong intensities connected to the identified "pleural line." Once the pleural line was reconstructed, the second step was to train the SVM classifier on eight parameters extracted from the geometric and intensity properties of the pleural line and the areas below the line. Such supervised classification required a smaller dataset compared to a deep neural network and was computed much faster. The labeling used a 4-level scoring system [35], from 0-healthy to 3-severe. The overall accuracy in identifying the pleural lines was $84 \%$ for convex and $94 \%$ for linear probes. The accuracy of the auto-classification using SVM was about $88 \%$ for convex and $94 \%$ for linear probes. 
Wang et al. extracted features of the pleural line (thickness, roughness, mean and standard deviation of pleura intensities) and B-lines (number, accumulated width, attenuation, and accumulated intensity) from 13 moderate, seven severe, and seven critical cases of COVID-19 pneumonia. For a binary comparison of severe/non-severe, several features showed statistically significant differences. An SVM classifier yielded a high area under the curve (AUC) of 0.96 , with a sensitivity of 0.93 and specificity of 1 [69]. One could also separate the evaluation into two steps of feature extraction and image classification [70]. Four CNN models (Resnet18, Resnet50, GoogleNet, and NASNet-Mobile) were tried to extract features from LUS images and then fed the features to the SVM classifier. For a dataset of 2995 images (988 COVID-19, 731 Pneumonia, and 1276 Regular), SVM classifiers reached exceptional results of accuracy, precision, recall, and F1-score (most exceeding $99 \%$ ), with all four set of features extracted by the four CNN models.

\subsubsection{Artificial Neural Network (ANN) Classifier}

Raghavi et al. tried the Hopfield neural network (a type of artificial neural network for human memory simulation) to classify a dataset with 266 positive COVID-19 and 499 negative cases (training/test: 80/20\%), achieving an accuracy of over $83.66 \%$ [71].

\subsection{Deep Learning (DL) Models}

Due to the increasing chip processing capability and reduced computational cost, deep learning (DL) has been a fast-developing subset of machine learning. Many DL architectures proposed for COVID-19 detection were based on convolutional neural networks (CNNs), trained with collected LUS datasets.

\subsubsection{Convolutional Neural Networks (CNNs)}

Born et al. trained a convolutional neural network (POCOVID-Net) on their POCUS dataset with 5-fold cross-validation [59]. They combined the convolutional part of VGG16 [72] with a hidden layer containing 64 neurons with ReLU activation. The trained classifier achieved an accuracy of 0.89 , a sensitivity of 0.96 , and a specificity of 0.79 in diagnosing COVID-19 pneumonia. Later, they used VGG-CAM (Class Activation Map (CAM)) or VGG to train three-class (COVID-19 pneumonia, bacterial pneumonia, and healthy controls) models on POCUS [60]. Both VGG-CAM and VGG yielded accuracies of 0.90. In January 2021, they extended the dataset and trained a frame-based classifier, yielding a sensitivity of 0.806 and a specificity of 0.962 [61]. Similarly, Diaz-Escobar et al. performed both three-class (COVID-19, bacterial pneumonia, and healthy) and binary (COVID-19 vs. bacterial and COVID-19 vs. healthy) classifications on POCUS, with pretrained DL models (VGG19, InceptionV3, Xception, and ResNet50) [73]. Their results showed that InceptionV3 worked best with an AUC of 0.97 to identify COVID-19 cases from pneumonia and healthy controls. Roberts et al. tested VGG16 and ResNet18, and their results from VGG16 outperformed the ResNet18 counterparts [74].

For the fully-annotated ICLUS-DB, Roy et al. proposed an auto-scoring process for image frames and videos separately, along with a pathological artifact segmentation method [62]. As for image frames, the anomalies or artifacts were automatically detected with the spatial transformer networks (STN). For two different STN crops taken from the same image, they regularized their scores to be consistent, so the method was named the regularized spatial transformer networks (Reg-STN). As for videos, scores reflect the overall distribution of frames in sequence by employing a softened aggregation function based on uninorms [75]. Their Reg-STN method outperformed all other tested baseline methods for frame-based classifications with an F1-score of $65.1 \%$. Their softened aggregation method outperformed the maximum and average baseline aggregation methods for video-based scoring, with an F1-score of $61 \pm 12 \%$. For auto-segmentation evaluation, their model achieved an accuracy of $96 \%$ at a pixel level. Yaron et al. tried to improve Roy's method by fixing the discrepancy between convex and linear probes, noticing the artifacts ("Blines") were tilting in convex probe images [76]. By rectifying the convex probe images 
from the polar coordinate, the artifacts would be axis-aligned like the linear probe, which simplified the DL architecture and yielded a higher F1 score compared to [62] over the same dataset. Reg-STN architectures were also applied on other COVID-19 datasets and achieved satisfactory accuracies of above 0.9 [77].

In another multicenter study, Mento et al. described standardized imaging protocols and scoring schemes in acquiring LUS videos. They trained DL algorithms on 82 confirmed patients and graded videos by aggregation of frame-based scores [78]. The prognostic agreement between DL models [62] and clinicians was $86 \%$ in predicting a high or low risk of clinical worsening [78]. Later for a larger dataset of 100 patients, the agreement between AI and clinicians was 82\% [79]. Demi et al. applied similar algorithms [78] in a longitudinal study with 220 patients (100 COVID-19 patients and 120 post-COVID-19 patients), and their prognostic agreement between AI and MDs was $80 \%$ for COVID-19 patients and $72.5 \%$ for post-COVID-19 patients [80].

Ebadi et al. proposed a deep video scoring method based on the Kinetics-I3D network, without the need for tedious frame-by-frame processing [81]. Pneumonia/ARDS features including A-lines, B-lines, consolidation and/or pleural effusion classes were detected from the video and compared with radiologists' results. They collected a dataset of 300 patients with 100 for each ARDS feature. Five-fold cross-validation results showed high ROC-AUCs of 0.91-0.96 for detecting the three ARDS features (A-lines, B-lines, consolidation and/or pleural effusion).

Since the COVID-19 LUS dataset include both videos and frames, the impact of various training/test splitting scheme should be evaluated [82]. Roshankhah et al. used manually segmented B-mode images and corresponding 4-scale staging scores as the ground truth for 1863 images from 203 videos (of 14 confirmed cases, four suspected cases, and 14 controls). They achieved a higher accuracy of $95 \%$ for image-level data splitting (training/test: $90 / 10 \%$ ) but a much lower accuracy $(<75 \%)$ for patient-level data splitting. The overestimation of image-level splitting may originate from the fact that the images from the same patient could be similar but randomly appear in both training and testing subsets.

Another underlying issue is the labeling effort for LUS videos or frames. Durrani et al. investigated the impact of labeling effort by comparing binary classification results from the frame-based method (higher labeling effort) versus the video-based method (lower labeling effort) [83]. They further introduced a third sampled quaternary method to annotate all frames based on only $10 \%$ positively labeled samples from the whole dataset, which outperformed the previous two labeling strategies. Gare et al. tried to convert a pre-trained segmentation model into a diagnostic classifier and compared the results from dense vs. sparse segmentation labeling [84]. Tested on a restricted dataset of 152 images from four patients (three COVID-19 positives and one control), they found that with pretrained segmentation weights and dense labeling pretrained U-net, the classifier performs best with an overall accuracy of 0.84 .

Considering the development of portable LUS and the need for rapid bedside detection, Awasthi et al. proposed a lightweight DL architecture of COVID-19 LUS diagnosis. The new method, namely Mini-CovidNet, modifies MobileNet with focal loss. Mini-CovidNet obtained an accuracy of 0.83 on the POCUS dataset [59], which is similar to POCOVID-Net. Still, the number of parameters was 4.39 times lesser in Mini-CovidNet, and thus consumed smaller memory, making it appealing to mobile platforms [85]. On the other hand, an interpretable subspace approximation with adjusted bias (Saab) multilayer network was proposed to read LUS images with low-complexity and low-power consumption, which appeals to personal devices [86].

\subsubsection{Hybrid Models: Combining CNNs with Other Methods}

Hybrid DL algorithms combining backbone CNNs with other units such as the long short-term memory (LSTM) were introduced to improve the model performance. Barros et al. tailored a hybrid CNN-LSTM model to classify LUS videos by extracting spatial features with CNNs and then learning the temporal dependence via LSTM [87]. Their 
hybrid model reached a higher accuracy of $93 \%$ and sensitivity of $97 \%$ for COVID-19 cases, compared to other primitive spatial-based models. Dastider et al. used the Italian LUS database (ICLUS-DB) to train a frame-based four-score CNN-based architecture with a backbone of DenseNet-201 [88]. After integrating the LSTM units (CNN-LSTM), the model performance improved by $7-12 \%$ compared to the original $\mathrm{CNN}$ architecture.

Besides LSTM units, other add-ons such as feature fusion or denoising could also help. A CNN-based classifier with a multilayer fusion functionality per block was also tested to enhance the performance and achieved high metrics of above 0.92 over the POCUS dataset [89]. Che et al. utilized a multiscale residual CNN with feature fusion strategy to evaluate a dataset consisting of both POCUS dataset and ICLUS-DB and obtained an average accuracy of 0.95 [90]. A spectral mask enhancement (SpecMEn) scheme was introduced to reduce the noise in the original LUS images; thus, the SpecMEn improved the accuracy and F1-score of DL models (CNN variants) by $11 \%$ and $11.75 \%$ on the POCUS dataset [91].

For COVID-19 diagnosis, plural lines and sub-plural symptom features in LUS are signatures of pneumonia severity [92], so some DL algorithms took advantage of the identification and segmentation of pleura, A-lines, and B-lines to improve pneumonia assessment. Baloescu et al. developed deep CNN to detect B-lines from 400 ultrasound clips and evaluate COVID-19 severity [93]. For binary classification of presence or absence of B-lines, they reached a sensitivity of 0.93 and a specificity of 0.96 . For multiscale severity based on B-lines, the model reached a weighted kappa of 0.65. Panicker et al. presented a method to first detect the pleura via extracted acoustic wave propagation features; after obtaining the region below pleura, the infection severity was classified with VGG-16 from input regions [94]. They achieved an accuracy, sensitivity, and specificity of $0.97,90.2$, and 0.98 , respectively, for 5000 video frames from ten patients over their infection to the full recovery phase. Considering the complexity of pathology behaviors for COVID-19, Liu et al. built a new LUS dataset with multiple COVID-19 symptoms (A-line, B-line, P-lesion, and P-effusion), namely COVID19-LUSMS, consisting of 71 patients [95]. They presented a semi-supervised two-stream active learning (TSAL) method with multi-label learning, and achieved high accuracies greater than 0.9 for A-line, B-line, and moderate accuracies greater than 0.8 for P-lesion and P-effusion. Such aid of artifacts detection improved the classification performance of the neural network.

One encouraging point about these LUS artifacts, such as B-lines, is that though they are related to pathology in various lung diseases, deep learning techniques could identify COVID-19 from other types of pneumonia [96]. Over a combined B-lines dataset consisting of 612 LUS videos from 243 patients with COVID-19, non-COVID acute respiratory distress syndrome, and hydrostatic pulmonary edema, the trained CNNs (Xception architecture) classifiers showed AUCs of 1.0, 0.934, and 1.0, respectively, much better than physician differentiation ability between these lung diseases [97].

\subsubsection{Multi-Modality Data and Transfer Learning}

Given several datasets of COVID-19 medical images are now available, the amount of total LUS data is still highly limited due to the short time of collecting images since the outbreak. To address the problem of scarcity of available medical images, multi-modality data was utilized to elevate model accuracy for small datasets.

In effort to treat the heterogeneous and multi-modality medical information, a duallevel supervised multiple instance learning module (DSA-MIL) was proposed to fuse the zone-level signatures to patient-level representations [98]. A modality alignment contrastive learning unit combined the representations of LUS and clinical information (such as age, disease history, respiratory, fever, and cough). A staged representation transfer (SRT) scheme was used for subsequent data training. Combining both modalities (LUS and clinical information), they achieved an accuracy of 0.75 for four-level severity scoring and 0.88 for the binary severe/non-severe classification. On the other hand, Zheng et al. built multimodal knowledge graphs from fused CT, X-ray, ultrasound, and text modalities, 
reaching a classification accuracy of 0.98 [99]. A multimodal channel and receptive field attention network combined with ResNeXt was proposed to process multicenter and multimodal data and achieved 0.94 accuracy [100].

Horry et al. searched COVID-19 chest X-rays [101], CT scans (COVID-19 and nonCOVID-19) [56], and ultrasound images (COVID-19, bacterial pneumonia and normal conditions) [59]. They compiled them into a multimodal imaging dataset for training [102]. To minimize the effect of sampling bias introduced by any systematic difference in pixel intensity between datasets, histogram equalization to images using the N-CLAHE method described by [103] was applied. They tried to achieve a reliable classification accuracy with transfer learning to compensate for the limited size of the sample datasets and accelerate the training process. Eight CNNs based models were tested: VGG16/VGG19, Resnet50, Inception V3, Xception, InceptionResNet, DenseNet, and NASNetLarge. As a result, the ultrasound mode yielded a sensitivity of 0.97 and a positive predictive value of 0.99 for normal cases; and a sensitivity of 1.0 and a positive predictive value of 1.0 for distinguishing COVID-19 from the bacterial pneumonia patients.

Karnes et al. explored a novel vocabulary-based few-shot learning (FSL) visual classification algorithm that utilized a pre-trained deep neural network (DNN) to compress images into features and further processed them to vocabulary and feature vector [104]. The knowledge of a pretrained DNN was transferred to new applications, and then only a few training parameters were needed, so the training dataset was largely reduced. Salvia et al. employed residual CNNs (ResNet18 and ResNet50), transfer learning, and data augmentation techniques for multi-level pathology gradings (four main levels and seven sub-levels) over a dataset of 450 patients [105]. For both ResNet18 and ResNet50, and for both four-level and seven-level classifications, the metrics were all above 0.97. By taking advantage of transfer learning, their model could classify the COVID-19 cases even with limited LUS data input.

A summary of the discussed AI research articles is listed in Table 2.

Table 2. Summary of research articles on AI applications of LUS for COVID-19.

\begin{tabular}{|c|c|c|c|c|c|}
\hline Articles & Time & Datasets & Techniques & Main Tasks & Results \\
\hline Born et al. [59] & May 2020 & $\begin{array}{c}\text { POCUS dataset [59]: } 64 \\
\text { videos (39 COVID-19, } 14 \\
\text { bacterial pneumonia, and } 11 \\
\text { healthy controls) }\end{array}$ & VGG16 & $\begin{array}{l}\text { Classifying frames/videos } \\
\text { as COVID-19, bacterial } \\
\text { pneumonia, or healthy. }\end{array}$ & $\begin{array}{l}\text { * AUC: } 0.94 \\
\text { Accuracy: } 0.89 \\
\text { Sensitivity: } 0.96 \\
\text { Specificity: } 0.79 \\
\text { F1-score: } 0.92\end{array}$ \\
\hline Roy et al. [62] & $\begin{array}{l}\text { August } \\
2020\end{array}$ & $\begin{array}{l}35 \text { patients (17 COVID-19, } 4 \\
\text { COVID-19 suspected, and } 14 \\
\text { healthy controls) }\end{array}$ & $\begin{array}{c}\text { Spatial Transformer } \\
\text { Networks (STN) \& } \\
\text { U-Net }\end{array}$ & $\begin{array}{l}\text { Scoring frames/videos; } \\
\text { Segmenting COVID-19 } \\
\text { imaging biomarkers. }\end{array}$ & $\begin{array}{c}\text { Accuracy: } 0.96 \\
\text { Recall: } 0.6 \pm 0.07 \\
\text { Precision: } 0.7 \pm 0.19 \\
\text { F1-score: } 0.61 \pm 0.12\end{array}$ \\
\hline $\begin{array}{l}\text { Horry et al. } \\
\text { [102] }\end{array}$ & $\begin{array}{l}\text { August } \\
2020\end{array}$ & $\begin{array}{l}\text { Multimodal dataset of X-ray, } \\
\text { ultrasound, and CT } \\
\text { (COVID-19, pneumonia, and } \\
\text { Normal) }\end{array}$ & $\begin{array}{c}\text { VGG16/19, } \\
\text { ResNet50, Inception } \\
\text { V3, Xception, } \\
\text { InceptionResNetV2, } \\
\text { NASNet, and } \\
\text { DenseNet121 }\end{array}$ & $\begin{array}{c}\text { Classifying COVID-19, } \\
\text { pneumonia, and normal } \\
\text { cases with limited datasets. }\end{array}$ & $\begin{array}{l}\text { Recall: } 1.0 \\
\text { Precision: } 1.0 \\
\text { F1-score: } 1.0\end{array}$ \\
\hline Born et al. [60] & $\begin{array}{c}\text { September } \\
2020\end{array}$ & $\begin{array}{c}139 \text { recordings (63 COVID-19, } \\
41 \text { non-COVID-19 } \\
\text { pneumonia, and } 35 \text { healthy } \\
\text { controls) }\end{array}$ & VGG16 & $\begin{array}{c}\text { Classifying COVID-19 US } \\
\text { videos; } \\
\text { Localizing } \\
\text { spatio-temporally } \\
\text { pulmonary biomarkers. }\end{array}$ & $\begin{array}{c}\text { AUC: } 0.94 \pm 0.03 \\
\text { Recall: } 0.98 \pm 0.04 \\
\text { Specificity: } 0.91 \pm 0.08 \\
\text { Precision: } 0.91 \pm 0.08 \\
\text { MCC: } 0.89 \pm 0.06 \\
\text { F1-score } 0.94 \pm 0.04\end{array}$ \\
\hline Hou et al. [86] & $\begin{array}{l}\text { October } \\
2020\end{array}$ & $\begin{array}{c}2800 \text { images (740 A-line, } 1150 \\
\text { B-line and } 910 \text { consolidation } \\
\text { images) }\end{array}$ & $\begin{array}{l}\text { Adjusted Bias (Saab) } \\
\text { multilayer network }\end{array}$ & $\begin{array}{l}\text { Classifying consolidation } \\
\text { vs A-line vs B-line. }\end{array}$ & Accuracy: 0.97 \\
\hline
\end{tabular}


Table 2. Cont.

\begin{tabular}{|c|c|c|c|c|c|}
\hline Articles & Time & Datasets & Techniques & Main Tasks & Results \\
\hline $\begin{array}{l}\text { Roberts et al. } \\
\text { [74] }\end{array}$ & $\begin{array}{l}\text { November } \\
2020\end{array}$ & POCUS dataset [59] & VGG16 \& ResNet18 & $\begin{array}{l}\text { Classifying COVID-19, } \\
\text { bacterial pneumonia, and } \\
\text { control cases. }\end{array}$ & $\begin{array}{l}\text { Accuracy: } 0.86 \\
\text { AUC: } 0.90\end{array}$ \\
\hline $\begin{array}{l}\text { Carrer et al. } \\
\text { [66] }\end{array}$ & $\begin{array}{l}\text { November } \\
2020\end{array}$ & $\begin{array}{l}\text { Subsets of the ICLUS-DB } \\
\text { database [66]: } 29 \text { cases (10 } \\
\text { negatives, } 15 \text { positives, and } \\
\text { four suspected COVID-19) }\end{array}$ & SVM & $\begin{array}{l}\text { Detecting pleural line } \\
\text { automatically; } \\
\text { Scoring LUS images. }\end{array}$ & $\begin{array}{l}\text { Accuracy: } 0.85-0.98 \\
\text { Sensitivity: } 0.85-0.93 \\
\text { Specificity: } 0.95-0.99\end{array}$ \\
\hline Liu et al. [95] & $\begin{array}{l}\text { November } \\
2020\end{array}$ & $\begin{array}{l}71 \text { patients with } 6836 \text { images } \\
\text { sampled from } 678 \text { videos }\end{array}$ & ResNet50 & $\begin{array}{l}\text { Classifying A-line, B-line, } \\
\text { pleural lesion, and pleural } \\
\text { effusion. }\end{array}$ & $\begin{array}{l}\text { Accuracy: } 0.98 \\
\text { Sensitivity: } 0.99 \\
\text { Specificity: } 0.92\end{array}$ \\
\hline $\begin{array}{c}\text { Baloescu et al. } \\
\text { [93] }\end{array}$ & $\begin{array}{l}\text { November } \\
2020\end{array}$ & $\begin{array}{l}2415 \text { subclips rated for } \\
\text { severity of B-lines, from } 0 \\
\text { (none) to } 4 \text { (severe) }\end{array}$ & $\begin{array}{l}\text { Custom-designed } \\
\text { CNNs }\end{array}$ & $\begin{array}{l}\text { Detecting B-lines from LUS } \\
\text { clips to evaluate COVID-19 } \\
\text { severity. }\end{array}$ & $\begin{array}{c}\text { AUC: } 0.97 \\
\text { Sensitivity: } 0.81-0.98 \\
\text { Specificity: } 0.84-0.99 \\
\text { Kappa: } 0.79-0.97\end{array}$ \\
\hline Che et al. [90] & $\begin{array}{l}\text { February } \\
2021\end{array}$ & $\begin{array}{c}\text { POCUS dataset and } \\
\text { ICLUS-DB: } 51 \text { COVID-19, } 13 \\
\text { pneumonia, and } 12 \text { healthy } \\
\text { subjects }\end{array}$ & ResNet & $\begin{array}{l}\text { Classifying COVID-19 from } \\
\text { LUS data. }\end{array}$ & $\begin{array}{l}\text { Accuracy: } 0.95 \\
\text { Recall: } 0.99 \\
\text { Precision: } 0.96 \\
\text { F1-score: } 0.9\end{array}$ \\
\hline $\begin{array}{l}\text { Muhammad } \\
\text { et al. [89] }\end{array}$ & $\begin{array}{l}\text { February } \\
2021\end{array}$ & $\begin{array}{l}121 \text { videos ( } 45 \text { for COVID-19, } \\
23 \text { for bacterial pneumonia, } \\
\text { and } 53 \text { for healthy); } \\
40 \text { images ( } 18 \text { for COVID-19, } \\
7 \text { for bacterial pneumonia, } \\
\text { and } 15 \text { for healthy) }\end{array}$ & ResF module & $\begin{array}{l}\text { Classifying COVID-19, } \\
\text { bacterial pneumonia, and } \\
\text { healthy cases. }\end{array}$ & $\begin{array}{c}\text { AUC: } 0.99 \\
\text { Accuracy: } 0.92 \\
\text { Recall: } 0.93 \\
\text { Precision: } 0.92\end{array}$ \\
\hline $\begin{array}{c}\text { Dastider et al. } \\
\text { [88] }\end{array}$ & $\begin{array}{l}\text { February } \\
2021\end{array}$ & $\begin{array}{l}\text { ICLUS-DB: } 58 \text { videos ( } 38 \text { with } \\
\text { a convex probe, and } 20 \text { with a } \\
\text { linear probe) scored based on } \\
\text { a } 4 \text {-level scoring system }\end{array}$ & DenseNet-201 & Scoring LUS images. & $\begin{array}{c}\text { Accuracy: } 0.79 \pm \\
0.06 / 0.68 \pm 0.03 \\
\text { Sensitivity: } 0.79 \pm \\
0.06 / 0.68 \pm 0.03 \\
\text { Specificity: } 0.90 \pm \\
0.03 / 0.77 \pm 0.14 \\
\text { F1-score: } 0.79 \pm \\
0.06 / 0.67 \pm 0.03\end{array}$ \\
\hline $\begin{array}{c}\text { Arntfield et al. } \\
\text { [97] }\end{array}$ & $\begin{array}{l}\text { February } \\
2021\end{array}$ & $\begin{array}{c}243 \text { patients ( } 81 \text { hydrostatic } \\
\text { pulmonary edema (HPE), } 78 \\
\text { non-COVID ARDS } \\
\text { (NCOVID), and } 84 \\
\text { COVID-19) }\end{array}$ & Xception & $\begin{array}{l}\text { Classifying COVID-19, } \\
\text { NCOVID and HPE } \\
\text { pathologies. }\end{array}$ & $\begin{array}{l}\text { AUC: } 0.97 \\
\text { Sensitivity: } 0.92 \\
\text { Specificity: } 0.88 \\
\text { Precision: } 0.71 \\
\text { F1-score } 0.81\end{array}$ \\
\hline Tsai et al. [77] & $\begin{array}{l}\text { March } \\
2021\end{array}$ & $\begin{array}{c}70 \text { patients ( } 39 \text { abnormal and } \\
31 \text { normal) }\end{array}$ & STN & $\begin{array}{l}\text { Classifying normal vs } \\
\text { pleural effusion classes. }\end{array}$ & $\begin{array}{l}\text { Accuracy: } 0.92 \\
\text { Recall: } 0.88 \\
\text { F1-score: } 0.9\end{array}$ \\
\hline Hu et al. [100] & $\begin{array}{l}\text { March } \\
2021\end{array}$ & $\begin{array}{l}\text { Multicenter and multimodal } \\
\text { ultrasound data from } 104 \\
\text { patients }\end{array}$ & ResNeXt & $\begin{array}{l}\text { Scoring lung sonograms } \\
\text { based on classifications of } \\
\text { pathology indicators. }\end{array}$ & $\begin{array}{l}\text { Accuracy: } 0.94 \\
\text { Sensitivity: } 0.76 \\
\text { Specificity: } 0.96 \\
\text { Precision: } 0.82\end{array}$ \\
\hline Xue et al. [98] & April 2021 & $\begin{array}{l}313 \text { patients classified into } \\
\text { four types (mild, moderate, } \\
\text { severe, and critical severe) }\end{array}$ & VGG & $\begin{array}{l}\text { Classifying severity of } \\
\text { COVID-19 patients from } \\
\text { LUS and clinical } \\
\text { information. }\end{array}$ & $\begin{array}{l}\text { Accuracy: } 0.88 \\
\text { Recall: } 0.85 \\
\text { Precision: } 0.8 \\
\text { F1-score: } 0.87\end{array}$ \\
\hline Gare et at. [84] & April 2021 & $\begin{array}{c}\text { Four patients (three } \\
\text { COVID-19 positives and one } \\
\text { control) }\end{array}$ & U-net & $\begin{array}{l}\text { Segmenting A-line, B-line, } \\
\text { and pleural line; } \\
\text { Classifying normal vs. } \\
\text { pneumonia vs. COVID-19. }\end{array}$ & $\begin{array}{l}\text { Accuracy: } 0.85 \\
\text { Recall: } 0.91 \\
\text { Precision: } 0.89 \\
\text { F1-score: } 0.90\end{array}$ \\
\hline $\begin{array}{l}\text { Mento et al. } \\
\text { [78] }\end{array}$ & May 2021 & $\begin{array}{l}1488 \text { videos from } 82 \text { patients, } \\
\text { scored } 0-3 \text { scales }\end{array}$ & $\begin{array}{l}\text { STN \& U-Net and } \\
\text { DeepLab v3+ }\end{array}$ & Scoring LUS videos. & Accuracy: 0.86 \\
\hline $\begin{array}{l}\text { Yaron et al. } \\
\text { [76] }\end{array}$ & June 2021 & $\begin{array}{c}35 \text { patients (17 COVID-19, } 4 \\
\text { COVID-19 suspected, and } 14 \\
\text { healthy controls) }\end{array}$ & Resnet18 & Scoring LUS frames. & F1-score: 0.69 \\
\hline $\begin{array}{l}\text { Raghavi et al. } \\
\text { [71] }\end{array}$ & June 2021 & $\begin{array}{c}765 \text { images ( } 266 \text { positive } \\
\text { COVID-19 and } 499 \text { negative } \\
\text { cases) }\end{array}$ & ANN & Classifying a LUS dataset. & Accuracy: 0.84 \\
\hline
\end{tabular}


Table 2. Cont.

\begin{tabular}{|c|c|c|c|c|c|}
\hline Articles & Time & Datasets & Techniques & Main Tasks & Results \\
\hline $\begin{array}{c}\text { Awasthi et al. } \\
\text { [85] }\end{array}$ & June 2021 & $\begin{array}{l}\text { POCUS dataset: } 64 \text { videos (11 } \\
\text { healthy, } 14 \text { pneumonia, and } \\
39 \text { COVID-19 patient) }\end{array}$ & MobileNet & $\begin{array}{c}\text { Classifying COVID-19, } \\
\text { bacterial pneumonia, and } \\
\text { healthy cases. }\end{array}$ & $\begin{array}{l}\text { Accuracy: } 0.83 \\
\text { Sensitivity: } 0.92 \\
\text { Specificity: } 0.71 \\
\text { Precision: } 0.83 \\
\text { F1-score: } 0.87\end{array}$ \\
\hline $\begin{array}{l}\text { Zheng et al. } \\
\text { [99] }\end{array}$ & June 2021 & $\begin{array}{l}\text { Multimodal dataset: } 1393 \\
\text { doctor-patient dialogues and } \\
3706 \text { images for COVID-19 } \\
\text { patients; and } 607 \text { dialogues } \\
\text { and 10,754 images for } \\
\text { non-COVID-19 patients }\end{array}$ & Temporal NN & $\begin{array}{l}\text { Classifying COVID-19 vs. } \\
\text { non-COVID-19 casese. }\end{array}$ & $\begin{array}{l}\text { Accuracy: } 0.98 \\
\text { Sensitivity: } 0.99 \\
\text { Specificity: } 0.99 \\
\text { Precision: } 0.99 \\
\text { AUC: } 0.99 \\
\text { F1-score: } 0.99\end{array}$ \\
\hline Sadik et al. [91] & July 2021 & POCUS dataset [59] & $\begin{array}{l}\text { DenseNet-201, } \\
\text { ResNet-152V2, } \\
\text { Xception, VGG19, } \\
\text { and ImageNet }\end{array}$ & $\begin{array}{l}\text { Classifying COVID-19, } \\
\text { pneumonia, and normal } \\
\text { cases. }\end{array}$ & $\begin{array}{l}\text { Accuracy: } 0.91 \\
\text { Sensitivity: } 0.91 \\
\text { Specificity: } 0.90 \\
\text { F1-score: } 0.90\end{array}$ \\
\hline $\begin{array}{l}\text { Barros et al. } \\
\quad[87]\end{array}$ & $\begin{array}{l}\text { August } \\
2021\end{array}$ & $\begin{array}{c}185 \text { videos (69 COVID-19, } 50 \\
\text { bacterial pneumonia, and } 66 \\
\text { healthy controls) }\end{array}$ & $\begin{array}{l}\text { POCOVID-Net, } \\
\text { DenseNet, ResNet, } \\
\text { Xception, and } \\
\text { NASNet }\end{array}$ & $\begin{array}{l}\text { Classifying COVID-19, } \\
\text { pneumonia, and normal } \\
\text { cases. }\end{array}$ & $\begin{array}{l}\text { Accuracy: } 0.91-0.93 \\
\text { Recall: } 0.84-0.97 \\
\text { Specificity: } 0.90-1.0 \\
\text { Precision: } 0.89-1.0 \\
\text { F1-score: } 0.86-0.95\end{array}$ \\
\hline $\begin{array}{l}\text { Diaz-Escobar } \\
\text { et al. [73] }\end{array}$ & $\begin{array}{l}\text { August } \\
2021\end{array}$ & $\begin{array}{c}3326 \text { images (1283 for } \\
\text { COVID-19, } 731 \text { for bacterial } \\
\text { pneumonia, and } 1312 \text { for } \\
\text { healthy controls) }\end{array}$ & $\begin{array}{l}\text { VGG19, InceptionV3, } \\
\text { Xception, and } \\
\text { ResNet50 }\end{array}$ & $\begin{array}{l}\text { Classifying COVID-19, } \\
\text { pneumonia, and normal } \\
\text { cases. }\end{array}$ & $\begin{array}{c}\text { AUC: } 0.97 \pm 0.01 \\
\text { Accuracy: } 0.89 \pm 0.02 \\
\text { Recall: } 0.86 \pm 0.03 \\
\text { F1-score: } 0.88 \pm 0.03 \\
\text { Precision: } 0.9 \pm 0.03\end{array}$ \\
\hline $\begin{array}{l}\text { Ebadi et al. } \\
\text { [81] }\end{array}$ & $\begin{array}{l}\text { August } \\
2021\end{array}$ & $\begin{array}{l}300 \text { patients (100 for each } \\
\text { ARDS feature: A-line, B-line, } \\
\text { and consolidation) }\end{array}$ & 3D ConvNet & $\begin{array}{c}\text { Classifying A-line, B-line, } \\
\text { and consolidation and/or } \\
\text { pleural effusion from } \\
\text { videos. }\end{array}$ & $\begin{array}{c}\text { AUC: } 0.91-0.96 \\
\text { Accuracy: } 0.9 \\
\text { Recall: } 0.86-0.92 \\
\text { Precision: } 0.93-0.98 \\
\text { F1-score: } 0.87-0.94\end{array}$ \\
\hline $\begin{array}{l}\text { La Salvia et al. } \\
\text { [105] }\end{array}$ & $\begin{array}{l}\text { August } \\
2021\end{array}$ & $\begin{array}{l}450 \text { patients ( } 278 \text { positive and } \\
172 \text { negative cases) }\end{array}$ & ResNet18, ResNet50 & $\begin{array}{l}\text { Classifying four/seven } \\
\text { classes of LUS. }\end{array}$ & $\begin{array}{l}\text { AUC: } 0.98-1.0 \\
\text { Accuracy: } 0.98-1.0 \\
\text { Recall: } 0.97-0.99 \\
\text { Precision: } 0.98-0.99 \\
\text { F1-score: } 0.97-0.99\end{array}$ \\
\hline $\begin{array}{l}\text { Panicker et al. } \\
\text { [94] }\end{array}$ & $\begin{array}{l}\text { September } \\
2021\end{array}$ & $\begin{array}{l}5000 \text { images from seven } \\
\text { subjects (1000 images per } \\
\text { class) }\end{array}$ & VGG16 & $\begin{array}{c}\text { Detecting pleura and } \\
\text { generating acoustic } \\
\text { features; } \\
\text { Classifying five classes of } \\
\text { LUS images. }\end{array}$ & $\begin{array}{l}\text { Accuracy: } 0.97 \\
\text { Sensitivity: } 0.92 \\
\text { Specificity: } 0.98\end{array}$ \\
\hline $\begin{array}{l}\text { Mento et al. } \\
\text { [79] }\end{array}$ & $\begin{array}{l}\text { September } \\
2021\end{array}$ & $\begin{array}{l}100 \text { patients with } 133 \text { LUS } \\
\text { exams scored to four levels }\end{array}$ & $\begin{array}{l}\text { STN \& U-Net and } \\
\text { DeepLab v3+ }\end{array}$ & Scoring LUS videos. & Accuracy: 0.82 \\
\hline $\begin{array}{c}\text { Al-Jumaili et al. } \\
\text { [70] }\end{array}$ & $\begin{array}{c}\text { October } \\
2021\end{array}$ & $\begin{array}{c}2995 \text { images (988 COVID-19, } \\
731 \text { pneumonia, and } 1276 \\
\text { regular images, available on } \\
\text { Kaggle) }\end{array}$ & $\begin{array}{l}\text { SVM \& Resnet18, } \\
\text { Resnet50, GoogleNet, } \\
\text { and NASNet-Mobile }\end{array}$ & $\begin{array}{c}\text { Detecting pathology } \\
\text { features from LUS images; } \\
\text { Classifying COVID-19, } \\
\text { pneumonia, and regular } \\
\text { cases. }\end{array}$ & $\begin{array}{l}\text { Accuracy: } 0.99 \\
\text { Sensitivity: } 0.99 \\
\text { Specificity: } 0.99 \\
\text { F1-score: } 0.99\end{array}$ \\
\hline $\begin{array}{c}\text { Karnes et al. } \\
\text { [104] }\end{array}$ & $\begin{array}{c}\text { October } \\
2021\end{array}$ & $\begin{array}{l}13103 \text { normal, } 4900 \\
\text { pneumonia, and } 8633 \\
\text { COVID-19 frames }\end{array}$ & LDA \& MobileNet & $\begin{array}{l}\text { Classifying COVID-19, } \\
\text { pneumonia, and healthy } \\
\text { cases. }\end{array}$ & AUC: 0.95 \\
\hline Demi et al. [80] & $\begin{array}{l}\text { December } \\
2021\end{array}$ & $\begin{array}{l}220 \text { patients ( } 100 \text { positive } \\
\text { patients and } 120 \\
\text { post-COVID-19 patients) }\end{array}$ & STN \& U-Net & $\begin{array}{l}\text { Testing protocols for } \\
\text { grading LUS. }\end{array}$ & Accuracy: 0.80 \\
\hline $\begin{array}{l}\text { Roshankhah } \\
\text { et al. [82] }\end{array}$ & $\begin{array}{l}\text { Decemberc } \\
\quad 2021\end{array}$ & $\begin{array}{l}32 \text { patients (14 confirmed } \\
\text { COVID-19, } 4 \text { suspected cases } \\
\text { and } 14 \text { controls) }\end{array}$ & U-Net & $\begin{array}{l}\text { Scoring severity in 4-scale } \\
\text { stages; } \\
\text { Investigating the impact of } \\
\text { various training/test } \\
\text { splitting schemes. }\end{array}$ & Accuracy: 0.95/0.75 \\
\hline Wang et al. [69] & $\begin{array}{l}\text { January } \\
2022\end{array}$ & $\begin{array}{l}27 \text { cases (13 moderate, seven } \\
\text { severe, and seven critical } \\
\text { cases of COVID-19) }\end{array}$ & SVM & $\begin{array}{l}\text { Scoring the severity of } \\
\text { COVID-19 pneumonia by } \\
\text { pleural line and B-lines. }\end{array}$ & $\begin{array}{l}\text { AUC: } 0.88-1.0 \\
\text { Sensitivity: } 0.93 \\
\text { Specificity: } 1.0\end{array}$ \\
\hline
\end{tabular}


Table 2. Cont.

\begin{tabular}{|c|c|c|c|c|c|}
\hline Articles & Time & Datasets & Techniques & Main Tasks & Results \\
\hline $\begin{array}{l}\text { Durrani et al. } \\
\text { [83] }\end{array}$ & July 2022 & $\begin{array}{l}28 \text { patients (10 unhealthy and } \\
18 \text { healthy) }\end{array}$ & STN \& U-Net & $\begin{array}{c}\text { Detecting } \\
\text { Consolidation/Collapse in } \\
\text { LUS videos/frames. }\end{array}$ & $\begin{array}{c}\text { AUC: } 0.73 \pm 0.3 \\
\text { Accuracy: } 0.89 \pm 0.16 \\
\text { Recall: } 0.84 \pm 0.23 \\
\text { Precision: } 0.59 \pm 0.28 \\
\text { F1-score: } 0.67 \pm 0.25\end{array}$ \\
\hline
\end{tabular}

* Area under curve (AUC).

\section{Challenges and Perspectives}

AI-based medical imaging has shown great potential in evaluating COVID-19 pneumonia [106,107], which could possibly be integrated within a user interface (UI) for decision support and report generation [108]. LUS is a safe, cost-effective, and convenient medical imaging modality, which has demonstrated the potential to serve as the first-line diagnosis tool, particularly in resource-challenged settings. The blooming of ML and DL on LUS is encouraging. Several ML architectures have been developed to differentiate and grade the COVID-19 in a standardized and accurate manner. Therefore, ML algorithms may gain growing value and set a new trend on shaping the LUS into a more reliable and automated tool for COVID-19 evaluation. The high accuracy auto-detection will largely save the clinicians time and effort in decision making and help to reduce possible interobserver errors.

Though many AI publications focused on binary classifications to differentiate COVID19 from normal or other pneumonia cases, a few multiscale ML classifiers aimed to score stages of pneumonia and diagnose pathology severity quantitatively [62,78-82,88,93,98,105]. These severity scores could be used in the triage and management of patients in clinical settings. Moreover, LUS can be routinely scanned if needed, without the risk of radiation exposure [16] and the burden of an over-complicated disinfection process [109]. Thus, these scores could also be used for monitoring the progress of the disease. It would be of interest to see more attempts on AI severity scoring from LUS and subsequent AI-enabled monitoring and triage workflow of COVID-19 patients.

Though AI-based LUS has many great advantages in the current COVID-19 pandemic, some challenges should be addressed. First, ultrasound poses a major limitation of the incapability of sound waves to penetrate deep into the lung tissues [23], so the deep lesions inside the lung cannot be properly reflected and reconstructed via LUS [110]. Besides poor penetration of sound wave signals for lung tissues, LUS results can be susceptible to the expertise of operators and thus induce low inter-annotator agreement [62,111]. Though ML and DL models aim to diagnose LUS free from human intervention, the training sets still require manual labeling, which may undermine the results. Cautions need to be taken during the labeling phase.

Another limitation comes from the dataset. It is difficult to find annotated LUS images from a large population of patients. This is because not only the online LUS datasets are scarce, but also the annotating process is time-consuming. Though many DL methods were proposed to address the problem, such as transfer learning on multimodal data, the generality of trained models is questionable with intrinsically small datasets. Besides the size of training datasets, the quality of input images could also impact the performance of ML algorithms. A recent study found that the performance of a previously validated DL algorithm worsened on new US machines, especially for a lower IQ, hand-held device [112]. Thus, all researchers are encouraged to contribute to large and comprehensive datasets. Despite these limitations, AI-based LUS is still highly valued in fast and sensible scans.

Nowadays, lightweight, portable ultrasound and telehealth are widely explored during the COVID-19 pandemic. Some studies use AI-robotics to perform tele-examination of patients [113,114], including a telerobotic system to scan LUS on a COVID patient [115]. These robot-assisted systems can increase the distance between sonographers and patients, thus minimizing the transmission risk [116]. In addition, Internet of Things (IoT) technolo- 
gies are integrated with cloud and AI to monitor and prognose COVID-19 disease [117,118]. In such cases, integration of AI-LUS with telerobotic systems and IoT could automate the process from acquiring imaging data to pneumonia diagnosis and disease monitoring, which will largely increase the efficiency of healthcare systems. Such AI-assisted clinical workflow promises great potential in the context of COVID-19 or other pandemics in the future.

\section{Conclusions}

AI-based LUS is an emerging technique to evaluate COVID-19 pneumonia. To improve the diagnosis efficiency of LUS, scoring systems and databases of LUS images are built for training ML models. An increasing number of ML architectures have been developed. They were able to achieve fairly high accuracy to differentiate the COVID-19 patients from both bacterial-related and other pneumonia cases and grade the pathology severity. In the future, with the increase of LUS datasets, more reliable AI algorithms could be developed and potentially help to diagnose and monitor viral pneumonia to reduce the tremendous burden to the global public health system.

Author Contributions: Conceptualization, T.L. and X.Y.; Methodology, J.W., X.Y. and T.L.; WritingOriginal Draft Preparation, J.W. and B.Z.; Writing-Review \& Editing, X.Y., B.Z., J.J.S., J.Z., J.T.J., K.A.H., J.D.B. and T.L. All authors have read and agreed to the published version of the manuscript.

Funding: This research received no external funding.

Institutional Review Board Statement: Not applicable.

Informed Consent Statement: Not applicable.

Data Availability Statement: Not applicable.

Acknowledgments: We thank Simone Henry for editing the manuscript.

Conflicts of Interest: The authors declare no conflict of interest.

\section{References}

1. Li, Q.; Guan, X.; Wu, P.; Wang, X.; Zhou, L.; Tong, Y.; Ren, R.; Leung, K.S.M.; Lau, E.H.Y.; Wong, J.Y.; et al. Early Transmission Dynamics in Wuhan, China, of Novel Coronavirus-Infected Pneumonia. N. Engl. J. Med. 2020, 382, 1199-1207. [CrossRef] [PubMed]

2. Huang, C.; Wang, Y.; Li, X.; Ren, L.; Zhao, J.; Hu, Y.; Zhang, L.; Fan, G.; Xu, J.; Gu, X. Clinical features of patients infected with 2019 novel coronavirus in Wuhan, China. Lancet 2020, 395, 497-506. [CrossRef]

3. Alharthy, A.; Faqihi, F.; Abuhamdah, M.; Noor, A.; Naseem, N.; Balhamar, A.; Saud, A.A.A.S.B.A.A.; Brindley, P.G.; Memish, Z.A.; Karakitsos, D.; et al. Prospective Longitudinal Evaluation of Point-of-Care Lung Ultrasound in Critically Ill Patients With Severe COVID-19 Pneumonia. J. Ultrasound Med. 2021, 40, 443-456. [CrossRef] [PubMed]

4. CDC. Interim Clinical Guidance for Management of Patients with Confirmed Coronavirus Disease (COVID-19). Available online: https: / www.cdc.gov/ coronavirus/2019-ncov/hcp/clinical-guidance-management-patients.html (accessed on 1 February 2022).

5. Stokes, E.K.; Zambrano, L.D.; Anderson, K.N.; Marder, E.P.; Raz, K.M.; Felix, S.E.B.; Tie, Y.; Fullerton, K.E. Coronavirus disease 2019 case surveillance-United States, 22 January-30 May 2020. MMWR 2020, 69, 759. [CrossRef] [PubMed]

6. Dong, D.; Tang, Z.; Wang, S.; Hui, H.; Gong, L.; Lu, Y.; Xue, Z.; Liao, H.; Chen, F.; Yang, F. The role of imaging in the detection and management of COVID-19: A review. IEEE Rev. Biomed. Eng. 2021, 14, 16-29. [CrossRef] [PubMed]

7. Harahwa, T.A.; Yau, T.H.L.; Lim-Cooke, M.-S.; Al-Haddi, S.; Zeinah, M.; Harky, A. The optimal diagnostic methods for COVID-19. Diagnosis 2020, 7, 349-356. [CrossRef]

8. Volpicelli, G.; Gargani, L. Sonographic signs and patterns of COVID-19 pneumonia. Ultrasound J. 2020, 12, 22. [CrossRef]

9. Jackson, K.; Butler, R.; Aujayeb, A. Lung ultrasound in the COVID-19 pandemic. Postgrad. Med. J. 2021, 97, 34-39. [CrossRef]

10. Farias, L.d.P.G.d.; Fonseca, E.K.U.N.; Strabelli, D.G.; Loureiro, B.M.C.; Neves, Y.C.S.; Rodrigues, T.P.; Chate, R.C.; Nomura, C.H.; Sawamura, M.V.Y.; Cerri, G.G. Imaging findings in COVID-19 pneumonia. Clinics 2020, 75, e2027. [CrossRef]

11. Aljondi, R.; Alghamdi, S. Diagnostic Value of Imaging Modalities for COVID-19: Scoping Review. J. Med. Internet Res. 2020, 22, e19673. [CrossRef]

12. Qian, X.; Wodnicki, R.; Kang, H.; Zhang, J.; Tchelepi, H.; Zhou, Q. Current Ultrasound Technologies and Instrumentation in the Assessment and Monitoring of COVID-19 Positive Patients. IEEE Trans. Ultrason. Ferroelectr. Freq. Control 2020, 67, 2230-2240. [CrossRef] [PubMed] 
13. Pata, D.; Valentini, P.; De Rose, C.; De Santis, R.; Morello, R.; Buonsenso, D. Chest Computed Tomography and Lung Ultrasound Findings in COVID-19 Pneumonia: A Pocket Review for Non-radiologists. Front. Med. 2020, 7, 375. [CrossRef] [PubMed]

14. Sultan, L.R.; Sehgal, C.M. A review of early experience in lung ultrasound (LUS) in the diagnosis and management of COVID-19. Ultrasound Med. Biol. 2020, 46, 2530-2545. [CrossRef] [PubMed]

15. Lichtenstein, D. Lung ultrasound in the critically ill. Ann. Intensive Care 2014, 4, 1. [CrossRef]

16. Copetti, R. Is lung ultrasound the stethoscope of the new millennium? Definitely yes. Acta Med. Acad. 2016, 45, 80-81. [CrossRef]

17. Mahase, E. COVID-19: What have we learnt about the new variant in the UK? BMJ 2020, 371, m4944. [CrossRef]

18. Mahase, E. COVID-19: What new variants are emerging and how are they being investigated? BMJ 2021, 372, n158. [CrossRef]

19. Wise, J. COVID-19: New coronavirus variant is identified in UK. BMJ 2020, 371, m4857. [CrossRef]

20. Lomoro, P.; Verde, F.; Zerboni, F.; Simonetti, I.; Borghi, C.; Fachinetti, C.; Natalizi, A.; Martegani, A. COVID-19 pneumonia manifestations at the admission on chest ultrasound, radiographs, and CT: Single-center study and comprehensive radiologic literature review. Eur. J. Radiol. Open 2020, 7, 100231. [CrossRef]

21. Musolino, A.M.; Supino, M.C.; Buonsenso, D.; Ferro, V.; Valentini, P.; Magistrelli, A.; Lombardi, M.H.; Romani, L.; D’Argenio, P.; Campana, A. Lung ultrasound in children with COVID-19: Preliminary findings. Ultrasound Med. Biol. 2020, 46, $2094-2098$. [CrossRef]

22. Zhang, Y.; Xue, H.; Wang, M.; He, N.; Lv, Z.; Cui, L. Lung Ultrasound Findings in Patients With Coronavirus Disease (COVID-19) AJR 2021, 216, 80-84. [CrossRef] [PubMed]

23. Huang, Y.; Wang, S.; Liu, Y.; Zhang, Y.; Zheng, C.; Zheng, Y.; Zhang, C.; Min, W.; Zhou, H.; Yu, M. A preliminary study on the ultrasonic manifestations of peripulmonary lesions of non-critical novel coronavirus pneumonia (COVID-19). SSRN Electron. J. 2020. in preprint. [CrossRef]

24. Buonsenso, D.; Piano, A.; Raffaelli, F.; Bonadia, N.; Donati, K.D.G.; Franceschi, F. Point-of-Care Lung Ultrasound findings in novel coronavirus disease-19 pnemoniae: A case report and potential applications during COVID-19 outbreak. Eur. Rev. Med. Pharmacol. Sci. 2020, 24, 2776-2780. [PubMed]

25. Bennett, D.; De Vita, E.; Mezzasalma, F.; Lanzarone, N.; Cameli, P.; Bianchi, F.; Perillo, F.; Bargagli, E.; Mazzei, M.A.; Volterrani, L.; et al. Portable Pocket-Sized Ultrasound Scanner for the Evaluation of Lung Involvement in Coronavirus Disease 2019 Patients. Ultrasound Med. Biol. 2021, 47, 19-24. [CrossRef] [PubMed]

26. Yasukawa, K.; Minami, T. Point-of-Care Lung Ultrasound Findings in Patients with COVID-19 Pneumonia. Am. J. Trop. Med. Hyg. 2020, 102, 1198-1202. [CrossRef]

27. Yassa, M.; Mutlu, M.A.; Birol, P.; Kuzan, T.Y.; Kalafat, E.; Usta, C.; Yavuz, E.; Keskin, I.; Tug, N. Lung ultrasonography in pregnant women during the COVID-19 pandemic: An interobserver agreement study among obstetricians. Ultrasonography 2020, 39, 340-349. [CrossRef]

28. Giorno, E.P.C.; De Paulis, M.; Sameshima, Y.T.; Weerdenburg, K.; Savoia, P.; Nanbu, D.Y.; Couto, T.B.; Sa, F.V.M.; Farhat, S.C.L.; Carvalho, W.B.; et al. Point-of-care lung ultrasound imaging in pediatric COVID-19. Ultrasound J. 2020, 12, 50. [CrossRef]

29. Soldati, G.; Smargiassi, A.; Inchingolo, R.; Buonsenso, D.; Perrone, T.; Briganti, D.F.; Perlini, S.; Torri, E.; Mariani, A.; Mossolani, E.E. Is there a role for lung ultrasound during the COVID-19 pandemic? J. Ultrasound Med. 2020, 39, 1459-1462. [CrossRef]

30. Tan, G.; Lian, X.; Zhu, Z.; Wang, Z.; Huang, F.; Zhang, Y.; Zhao, Y.; He, S.; Wang, X.; Shen, H. Use of lung ultrasound to differentiate COVID-19 pneumonia from community-acquired pneumonia. Ultrasound Med. Biol. 2020, 46, 2651-2658. [CrossRef]

31. Lyu, G.; Zhang, Y.; Tan, G. Transthoracic ultrasound evaluation of pulmonary changes in COVID-19 patients during treatment using modified protocols. Adv. Ultrasound Diagn. Ther. 2020, 4, 79-83.

32. Soummer, A.; Perbet, S.; Brisson, H.; Arbelot, C.; Constantin, J.-M.; Lu, Q.; Rouby, J.-J.; Bouberima, M.; Roszyk, L.; Bouhemad, B.; et al. Ultrasound assessment of lung aeration loss during a successful weaning trial predicts postextubation distress. Crit. Care Med. 2012, 40, 2064-2072. [CrossRef]

33. Copetti, R.; Cattarossi, L. Ultrasound diagnosis of pneumonia in children. Radiol. Med. 2008, 113, 190-198. [CrossRef] [PubMed]

34. Moro, F.; Buonsenso, D.; Moruzzi, M.C.; Inchingolo, R.; Smargiassi, A.; Demi, L.; Larici, A.R.; Scambia, G.; Lanzone, A.; Testa, A.C. How to perform lung ultrasound in pregnant women with suspected COVID-19. Ultrasound Obstet. Gynecol. 2020, 55, 593-598. [CrossRef] [PubMed]

35. Soldati, G.; Smargiassi, A.; Inchingolo, R.; Buonsenso, D.; Perrone, T.; Briganti, D.F.; Perlini, S.; Torri, E.; Mariani, A.; Mossolani, E.E. Proposal for international standardization of the use of lung ultrasound for COVID-19 patients; a simple, quantitative, reproducible method. J. Ultrasound Med. 2020, 39, 1413-1419. [CrossRef] [PubMed]

36. Lichtenstein, D. Novel approaches to ultrasonography of the lung and pleural space: Where are we now? Breathe 2017, 13, 100-111. [CrossRef]

37. Lichtenstein, D.A.; Mezière, G.A. The BLUE-points: Three standardized points used in the BLUE-protocol for ultrasound assessment of the lung in acute respiratory failure. Crit. Ultrasound J. 2011, 3, 109-110. [CrossRef]

38. Lichtenstein, D.A.; Mezière, G.A. Relevance of Lung Ultrasound in the Diagnosis of Acute Respiratory Failure*: The BLUE Protocol. Chest 2008, 134, 117-125. [CrossRef]

39. Tung-Chen, Y. Lung ultrasound in the monitoring of COVID-19 infection. Clin. Med. 2020, 20, e62-e65. [CrossRef]

40. Lichtenstein, D.A. Introduction to Lung Ultrasound. In Whole Body Ultrasonography in the Critically Ill; Springer: Berlin/Heidelberg, Germany, 2010; pp. 117-127. 
41. Soldati, G.; Demi, M.; Smargiassi, A.; Inchingolo, R.; Demi, L. The role of ultrasound lung artifacts in the diagnosis of respiratory diseases. Expert Rev. Respir. Med. 2019, 13, 163-172. [CrossRef]

42. van Sloun, R.J.G.; Demi, L. Localizing B-Lines in Lung Ultrasonography by Weakly Supervised Deep Learning, In-Vivo Results. IEEE J. Biomed. Health Inform. 2020, 24, 957-964. [CrossRef]

43. Smith, M.J.; Hayward, S.A.; Innes, S.M.; Miller, A.S.C. Point-of-care lung ultrasound in patients with COVID-19-A narrative review. Anaesthesia 2020, 75, 1096-1104. [CrossRef]

44. Buda, N.; Segura-Grau, E.; Cylwik, J.; Wełnicki, M. Lung ultrasound in the diagnosis of COVID-19 infection-A case series and review of the literature. Adv. Med. Sci. 2020, 65, 378-385. [CrossRef] [PubMed]

45. Peh, W.M.; Chan, S.K.T.; Lee, Y.L.; Gare, P.S.; Ho, V.K. Lung ultrasound in a Singapore COVID-19 intensive care unit patient and a review of its potential clinical utility in pandemic. J. Ultrason. 2020, 20, e154-e158. [CrossRef] [PubMed]

46. Convissar, D.; Gibson, L.E.; Berra, L.; Bittner, E.A.; Chang, M.G. Application of Lung Ultrasound During the Coronavirus Disease 2019 Pandemic: A Narrative Review. Anesth. Analg. 2020, 131, 345-350. [CrossRef] [PubMed]

47. Gargani, L.; Soliman-Aboumarie, H.; Volpicelli, G.; Corradi, F.; Pastore, M.C.; Cameli, M. Why, when, and how to use lung ultrasound during the COVID-19 pandemic: Enthusiasm and caution. Eur. Heart J. Cardiovasc. Imaging 2020, 21, 941-948. [CrossRef] [PubMed]

48. Peng, Q.-Y.; Wang, X.-T.; Zhang, L.-N.; Group, C.C.C.U.S. Findings of lung ultrasonography of novel corona virus pneumonia during the 2019-2020 epidemic. Intensive Care Med. 2020, 46, 849-850. [CrossRef] [PubMed]

49. Gil-Rodrigo, A.; Llorens, P.; Martínez-Buendía, C.; Luque-Hernández, M.-J.; Espinosa, B.; Ramos-Rincón, J.M. Diagnostic yield of point-of-care ultrasound imaging of the lung in patients with COVID-19. Emerg. Rev. Soc. Esp. Med. Emerg. 2020, 32, 340-344.

50. Castelao, J.; Graziani, D.; Soriano, J.B.; Izquierdo, J.L. Findings and Prognostic Value of Lung Ultrasound in COVID-19 Pneumonia. J. Ultrasound Med. 2021, 40, 1315-1324. [CrossRef]

51. Kalafat, E.; Yaprak, E.; Cinar, G.; Varli, B.; Ozisik, S.; Uzun, C.; Azap, A.; Koc, A. Lung ultrasound and computed tomographic findings in pregnant woman with COVID-19. Ultrasound Obstet. Gynecol. 2020, 55, 835-837. [CrossRef]

52. Volpicelli, G.; Lamorte, A.; Villén, T. What's new in lung ultrasound during the COVID-19 pandemic. Intensive Care Med. 2020, 46, 1445-1448. [CrossRef]

53. Deng, Q.; Zhang, Y.; Wang, H.; Chen, L.; Yang, Z.; Peng, Z.; Liu, Y.; Feng, C.; Huang, X.; Jiang, N. Semiquantitative lung ultrasound scores in the evaluation and follow-up of critically ill patients with COVID-19: A single-center study. Acad. Radiol. 2020, 27, 1363-1372. [CrossRef]

54. Lichter, Y.; Topilsky, Y.; Taieb, P.; Banai, A.; Hochstadt, A.; Merdler, I.; Gal Oz, A.; Vine, J.; Goren, O.; Cohen, B.; et al. Lung ultrasound predicts clinical course and outcomes in COVID-19 patients. Intensive Care Med. 2020, 46, 1873-1883. [CrossRef] [PubMed]

55. Wynants, L.; Calster, B.V.; Collins, G.S.; Riley, R.D.; Heinze, G.; Schuit, E.; Bonten, M.M.J.; Dahly, D.L.; Damen, J.A.A.; Debray, T.P.A.; et al. Prediction models for diagnosis and prognosis of COVID-19: Systematic review and critical appraisal. BMJ 2020, 369, m1328. [CrossRef] [PubMed]

56. Yang, X.; He, X.; Zhao, J.; Zhang, Y.; Zhang, S.; Xie, P. COVID-CT-Dataset: A CT Scan Dataset about COVID-19. arXiv 2020, arXiv:2003.13865.

57. Wang, L.; Wong, A. COVID-Net: A Tailored Deep Convolutional Neural Network Design for Detection of COVID-19 Cases from Chest X-ray Images. arXiv 2020, arXiv:2003.09871. [CrossRef]

58. Sohan, M.F. So You Need Datasets for Your COVID-19 Detection Research Using Machine Learning? arXiv 2020, arXiv:2008.05906.

59. Born, J.; Brändle, G.; Cossio, M.; Disdier, M.; Goulet, J.; Roulin, J.; Wiedemann, N. POCOVID-Net: Automatic detection of COVID-19 from a new lung ultrasound imaging dataset (POCUS). arXiv 2020, arXiv:2004.12084. in preprint.

60. Born, J.; Wiedemann, N.; Brändle, G.; Buhre, C.; Rieck, B.; Borgwardt, K. Accelerating COVID-19 Differential Diagnosis with Explainable Ultrasound Image Analysis. arXiv 2020, arXiv:2009.06116. in preprint.

61. Born, J.; Wiedemann, N.; Cossio, M.; Buhre, C.; Brändle, G.; Leidermann, K.; Aujayeb, A.; Moor, M.; Rieck, B.; Borgwardt, K. Accelerating detection of lung pathologies with explainable ultrasound image analysis. Appl. Sci. 2021, 11, 672. [CrossRef]

62. Roy, S.; Menapace, W.; Oei, S.; Luijten, B.; Fini, E.; Saltori, C.; Huijben, I.; Chennakeshava, N.; Mento, F.; Sentelli, A. Deep learning for classification and localization of COVID-19 markers in point-of-care lung ultrasound. IEEE Trans. Med. Imaging 2020, 39, 2676-2687. [CrossRef]

63. Ebadi, A.; Xi, P.; MacLean, A.; Tremblay, S.; Kohli, S.; Wong, A. COVIDx-US-An open-access benchmark dataset of ultrasound imaging data for AI-driven COVID-19 analytics. arXiv 2021, arXiv:2103.10003. in preprint.

64. Mohamed Ali, A.-M.; El-Alali, E.; Weltz, A.S.; Rehrig, S.T. Thoracic Point-of-Care Ultrasound: A SARS-CoV-2 Data Repository for Future Artificial Intelligence and Machine Learning. Surg. Innov. 2021, 28, 214-219. [CrossRef] [PubMed]

65. Campos, M.S.R.; Bautista, S.S.; Guerrero, J.V.A.; Suárez, S.C.; López, J.M.L. COVID-19 Related Pneumonia Detection in Lung Ultrasound. In Proceedings of the Mexican Conference on Pattern Recognition, Mexico City, Mexico, 23-26 June 2021; pp. 316-324.

66. Carrer, L.; Donini, E.; Marinelli, D.; Zanetti, M.; Mento, F.; Torri, E.; Smargiassi, A.; Inchingolo, R.; Soldati, G.; Demi, L.; et al. Automatic Pleural Line Extraction and COVID-19 Scoring From Lung Ultrasound Data. IEEE Trans. Ultrason. Ferroelectr. Freq. Control 2020, 67, 2207-2217. [CrossRef] [PubMed]

67. Maitra, R.; Faden, D. Noise Estimation in Magnitude MR Datasets. IEEE Trans. Med. Imaging 2009, 28, 1615-1622. [CrossRef] [PubMed] 
68. Carrer, L.; Bruzzone, L. Automatic Enhancement and Detection of Layering in Radar Sounder Data Based on a Local Scale Hidden Markov Model and the Viterbi Algorithm. IEEE Trans. Geosci. Remote Sens. 2017, 55, 962-977. [CrossRef]

69. Wang, Y.; Zhang, Y.; He, Q.; Liao, H.; Luo, J. Quantitative analysis of pleural line and B-lines in lung ultrasound images for severity assessment of COVID-19 pneumonia. IEEE Trans. Ultrason. Ferroelectr. Freq. Control 2022, 69, 73-83. [CrossRef]

70. Al-Jumaili, S.; Duru, A.D.; Uçan, O.N. COVID-19 Ultrasound image classification using SVM based on kernels deduced from Convolutional neural network. In Proceedings of the 2021 5th International Symposium on Multidisciplinary Studies and Innovative Technologies (ISMSIT), Ankara, Turkey, 21-23 October 2021; pp. 429-433.

71. Raghavi, K.; Vempati, K. Identify and Locate COVID-19 Point-of-Care Lung Ultrasound Markers by Using Deep Learning Technique Hopfield Neural Network. JES 2021, 12, 595-599.

72. Simonyan, K.; Zisserman, A. Very Deep Convolutional Networks for Large-Scale Image Recognition. arXiv 2015, arXiv:1409.1556.

73. Diaz-Escobar, J.; Ordóñez-Guillén, N.E.; Villarreal-Reyes, S.; Galaviz-Mosqueda, A.; Kober, V.; Rivera-Rodriguez, R.; Lozano Rizk, J.E. Deep-learning based detection of COVID-19 using lung ultrasound imagery. PLoS ONE 2021, 16, e0255886. [CrossRef]

74. Roberts, J.; Tsiligkaridis, T. Ultrasound Diagnosis of COVID-19: Robustness and Explainability. arXiv 2020, arXiv:2012.01145. in preprint.

75. Yager, R.R.; Rybalov, A. Uninorm aggregation operators. Fuzzy Sets Syst. 1996, 80, 111-120. [CrossRef]

76. Yaron, D.; Keidar, D.; Goldstein, E.; Shachar, Y.; Blass, A.; Frank, O.; Schipper, N.; Shabshin, N.; Grubstein, A.; Suhami, D. Point of Care Image Analysis for COVID-19. In Proceedings of the ICASSP 2021-2021 IEEE International Conference on Acoustics, Speech and Signal Processing (ICASSP), Toronto, ON, Canada, 6-11 June 2021; pp. 8153-8157.

77. Tsai, C.-H.; van der Burgt, J.; Vukovic, D.; Kaur, N.; Demi, L.; Canty, D.; Wang, A.; Royse, A.; Royse, C.; Haji, K. Automatic deep learning-based pleural effusion classification in lung ultrasound images for respiratory pathology diagnosis. Phys. Med. 2021, 83, 38-45. [CrossRef] [PubMed]

78. Mento, F.; Perrone, T.; Fiengo, A.; Smargiassi, A.; Inchingolo, R.; Soldati, G.; Demi, L. Deep learning applied to lung ultrasound videos for scoring COVID-19 patients: A multicenter study. J. Acoust. Soc. Am. 2021, 149, 3626-3634. [CrossRef] [PubMed]

79. Mento, F.; Perrone, T.; Fiengo, A.; Macioce, V.N.; Tursi, F.; Smargiassi, A.; Inchingolo, R.; Demi, L. A Multicenter Study Assessing Artificial Intelligence Capability in Scoring Lung Ultrasound Videos of COVID-19 Patients. In Proceedings of the 2021 IEEE International Ultrasonics Symposium (IUS), Xi'an, China, 11-16 September 2021; pp. 1-3.

80. Demi, L.; Mento, F.; Di Sabatino, A.; Fiengo, A.; Sabatini, U.; Macioce, V.N.; Robol, M.; Tursi, F.; Sofia, C.; Di Cienzo, C. Lung Ultrasound in COVID-19 and Post-COVID-19 Patients, an Evidence-Based Approach. J. Ultrasound Med. 2021, 9999, 1-13. [CrossRef] [PubMed]

81. Ebadi, S.E.; Krishnaswamy, D.; Bolouri, S.E.S.; Zonoobi, D.; Greiner, R.; Meuser-Herr, N.; Jaremko, J.L.; Kapur, J.; Noga, M.; Punithakumar, K. Automated detection of pneumonia in lung ultrasound using deep video classification for COVID-19. Inform. Med. Unlocked 2021, 25, 100687. [CrossRef]

82. Roshankhah, R.; Karbalaeisadegh, Y.; Greer, H.; Mento, F.; Soldati, G.; Smargiassi, A.; Inchingolo, R.; Torri, E.; Perrone, T.; Aylward, S. Investigating training-test data splitting strategies for automated segmentation and scoring of COVID-19 lung ultrasound images. J. Acoust. Soc. Am. 2021, 150, 4118-4127. [CrossRef]

83. Durrani, N.; Vukovic, D.; Antico, M.; Burgt, J.v.d.; van van Sloun, R.J.; Demi, L.; CANTY, D.; Wang, A.; ROYSE, A.; ROYSE, C. Automatic Deep Learning-Based Consolidation/Collapse Classification in Lung Ultrasound Images for COVID-19 Induced Pneumonia. TechRxiv 2022. in preprint. [CrossRef]

84. Gare, G.R.; Schoenling, A.; Philip, V.; Tran, H.V.; Bennett, P.d.; Rodriguez, R.L.; Galeotti, J.M. Dense Pixel-Labeling For ReverseTransfer And Diagnostic Learning On Lung Ultrasound For COVID-19 And Pneumonia Detection. In Proceedings of the 2021 IEEE 18th International Symposium on Biomedical Imaging (ISBI), Nice, France, 13-16 April 2021; pp. 1406-1410.

85. Awasthi, N.; Dayal, A.; Cenkeramaddi, L.R.; Yalavarthy, P.K. Mini-COVIDNet: Efficient Lightweight Deep Neural Network for Ultrasound Based Point-of-Care Detection of COVID-19. IEEE Trans. Ultrason. Ferroelectr. Freq. Control 2021, 68, $2023-2037$. [CrossRef]

86. Hou, D.; Hou, R.; Hou, J. Interpretable Saab Subspace Network for COVID-19 Lung Ultrasound Screening. In Proceedings of the 2020 11th IEEE Annual Ubiquitous Computing, Electronics \& Mobile Communication Conference (UEMCON), New York, NY, USA, 28-31 October 2020; pp. 393-398.

87. Barros, B.; Lacerda, P.; Albuquerque, C.; Conci, A. Pulmonary COVID-19: Learning spatiotemporal features combining cnn and lstm networks for lung ultrasound video classification. Sensors 2021, 21, 5486. [CrossRef]

88. Dastider, A.G.; Sadik, F.; Fattah, S.A. An integrated autoencoder-based hybrid CNN-LSTM model for COVID-19 severity prediction from lung ultrasound. Comput. Biol. Med. 2021, 132, 104296. [CrossRef]

89. Muhammad, G.; Hossain, M.S. COVID-19 and non-COVID-19 classification using multi-layers fusion from lung ultrasound images. Inf. Fusion 2021, 72, 80-88. [CrossRef]

90. Che, H.; Radbel, J.; Sunderram, J.; Nosher, J.L.; Patel, V.M.; Hacihaliloglu, I. Multi-Feature Multi-Scale CNN-Derived COVID-19 Classification from Lung Ultrasound Data. arXiv 2021, arXiv:2102.11942. in preprint.

91. Sadik, F.; Dastider, A.G.; Fattah, S.A. SpecMEn-DL: Spectral mask enhancement with deep learning models to predict COVID-19 from lung ultrasound videos. Health Inf. Sci. Syst. 2021, 9, 28. [CrossRef] [PubMed]

92. Gare, G.R.; Chen, W.; Hung, A.L.Y.; Chen, E.; Tran, H.V.; Fox, T.; Lowery, P.; Zamora, K.; DeBoisblanc, B.P.; Rodriguez, R.L.; et al. The Role of Pleura and Adipose in Lung Ultrasound AI. In Proceedings of the Clinical Image-Based Procedures, Distributed and 
Collaborative Learning, Artificial Intelligence for Combating COVID-19 and Secure and Privacy-Preserving Machine Learning, Strasbourg, France, 27 September-1 October 2021; pp. 141-149.

93. Baloescu, C.; Toporek, G.; Kim, S.; McNamara, K.; Liu, R.; Shaw, M.M.; McNamara, R.L.; Raju, B.I.; Moore, C.L. Automated lung ultrasound B-Line assessment using a deep learning algorithm. IEEE Trans. Ultrason. Ferroelectr. Freq. Control 2020, 67, 2312-2320. [CrossRef] [PubMed]

94. Panicker, M.R.; Chen, Y.T.; Gayathri, M.; Madhavanunni, N.; Narayan, K.V.; Kesavadas, C.; Vinod, A. Employing acoustic features to aid neural networks towards platform agnostic learning in lung ultrasound imaging. In Proceedings of the $2021 \mathrm{IEEE}$ International Conference on Image Processing (ICIP), Anchorage, AK, USA, 19-22 September 2021; pp. 170-174.

95. Liu, L.; Lei, W.; Wan, X.; Liu, L.; Luo, Y.; Feng, C. Semi-Supervised Active Learning for COVID-19 Lung Ultrasound Multisymptom Classification. In Proceedings of the 2020 IEEE 32nd International Conference on Tools with Artificial Intelligence (ICTAI), Baltimore, MD, USA, 9-11 November 2020; pp. 1268-1273.

96. Mason, H.; Cristoni, L.; Walden, A.; Lazzari, R.; Pulimood, T.; Grandjean, L.; Wheeler-Kingshott, C.A.; Hu, Y.; Baum, Z. Lung Ultrasound Segmentation and Adaptation Between COVID-19 and Community-Acquired Pneumonia. In Proceedings of the International Workshop on Advances in Simplifying Medical Ultrasound, Strasbourg, France, 27 September $2021 ;$ pp. $45-53$.

97. Arntfield, R.; VanBerlo, B.; Alaifan, T.; Phelps, N.; White, M.; Chaudhary, R.; Ho, J.; Wu, D. Development of a convolutional neural network to differentiate among the etiology of similar appearing pathological B lines on lung ultrasound: A deep learning study. BMJ Open 2021, 11, e045120. [CrossRef]

98. Xue, W.; Cao, C.; Liu, J.; Duan, Y.; Cao, H.; Wang, J.; Tao, X.; Chen, Z.; Wu, M.; Zhang, J. Modality alignment contrastive learning for severity assessment of COVID-19 from lung ultrasound and clinical information. Med. Image Anal. 2021, 69, 101975. [CrossRef] [PubMed]

99. Zheng, W.; Yan, L.; Gou, C.; Zhang, Z.-C.; Zhang, J.J.; Hu, M.; Wang, F.-Y. Pay attention to doctor-patient dialogues: Multi-modal knowledge graph attention image-text embedding for COVID-19 diagnosis. Inf. Fusion 2021, 75, 168-185. [CrossRef]

100. Hu, Z.; Liu, Z.; Dong, Y.; Liu, J.; Huang, B.; Liu, A.; Huang, J.; Pu, X.; Shi, X.; Yu, J. Evaluation of lung involvement in COVID-19 pneumonia based on ultrasound images. Biomed. Eng. Online 2021, 20, 27. [CrossRef]

101. Cohen, J.P.; Morrison, P.; Dao, L.; Roth, K.; Duong, T.Q.; Ghassemi, M. COVID-19 Image Data Collection: Prospective Predictions Are the Future. arXiv 2020, arXiv:2006.11988.

102. Horry, M.J.; Chakraborty, S.; Paul, M.; Ulhaq, A.; Pradhan, B.; Saha, M.; Shukla, N. COVID-19 detection through transfer learning using multimodal imaging data. IEEE Access 2020, 8, 149808-149824. [CrossRef]

103. Koonsanit, K.; Thongvigitmanee, S.; Pongnapang, N.; Thajchayapong, P. Image enhancement on digital X-ray images using N-CLAHE. In Proceedings of the 2017 10th Biomedical Engineering International Conference (BMEiCON), Hokkaido, Japan, 31 August-2 September 2017; pp. 1-4.

104. Karnes, M.; Perera, S.; Adhikari, S.; Yilmaz, A. Adaptive Few-Shot Learning PoC Ultrasound COVID-19 Diagnostic System. In Proceedings of the 2021 IEEE Biomedical Circuits and Systems Conference (BioCAS), Berlin, Germany, 7-19 October 2021; pp. 1-6.

105. La Salvia, M.; Secco, G.; Torti, E.; Florimbi, G.; Guido, L.; Lago, P.; Salinaro, F.; Perlini, S.; Leporati, F. Deep learning and lung ultrasound for COVID-19 pneumonia detection and severity classification. Comput. Biol. Med. 2021, 136, 104742. [CrossRef]

106. Huang, S.; Yang, J.; Fong, S.; Zhao, Q. Artificial intelligence in the diagnosis of COVID-19: Challenges and perspectives. Int. J. Biol. Sci. 2021, 17, 1581. [CrossRef]

107. Alyasseri, Z.A.A.; Al-Betar, M.A.; Doush, I.A.; Awadallah, M.A.; Abasi, A.K.; Makhadmeh, S.N.; Alomari, O.A.; Abdulkareem, K.H.; Adam, A.; Damasevicius, R. Review on COVID-19 diagnosis models based on machine learning and deep learning approaches. Expert Syst. 2021, e12759. [CrossRef] [PubMed]

108. Chuna, A.G.; Pavlova, M.; Gunraj, H.; Terhljan, N.; MacLean, A.; Aboutalebi, H.; Surana, S.; Zhao, A.; Abbasi, S.; Wong, A. COVID-Net MLSys: Designing COVID-Net for the Clinical Workflow. In Proceedings of the 2021 IEEE Canadian Conference on Electrical and Computer Engineering (CCECE), Virtual, Canada, 12-17 September 2021; pp. 1-5.

109. Gandhi, D.; Jain, N.; Khanna, K.; Li, S.; Patel, L.; Gupta, N. Current role of imaging in COVID-19 infection with recent recommendations of point of care ultrasound in the contagion: A narrative review. Ann. Transl. Med. 2020, 8. [CrossRef] [PubMed]

110. Khalili, N.; Haseli, S.; Iranpour, P. Lung Ultrasound in COVID-19 Pneumonia: Prospects and Limitations. Acad. Radiol. 2020, 27, 1044-1045. [CrossRef] [PubMed]

111. Gullett, J.; Donnelly, J.P.; Sinert, R.; Hosek, B.; Fuller, D.; Hill, H.; Feldman, I.; Galetto, G.; Auster, M.; Hoffmann, B. Interobserver agreement in the evaluation of B-lines using bedside ultrasound. J. Crit. Care 2015, 30, 1395-1399. [CrossRef]

112. Blaivas, M.; Blaivas, L.N.; Tsung, J.W. Deep Learning Pitfall. J. Ultrasound Med. 2021. (Online version). [CrossRef]

113. Feizi, N.; Tavakoli, M.; Patel, R.V.; Atashzar, S.F. Robotics and ai for teleoperation, tele-assessment, and tele-training for surgery in the era of COVID-19: Existing challenges, and future vision. Front. Robot. AI 2021, 8, 610677. [CrossRef]

114. Al-Zogbi, L.; Singh, V.; Teixeira, B.; Ahuja, A.; Bagherzadeh, P.S.; Kapoor, A.; Saeidi, H.; Fleiter, T.; Krieger, A. Autonomous Robotic Point-of-Care Ultrasound Imaging for Monitoring of COVID-19-Induced Pulmonary Diseases. Front. Robot. AI 2021, 8, 645756. [CrossRef]

115. Wang, J.; Peng, C.; Zhao, Y.; Ye, R.; Hong, J.; Huang, H.; Chen, L. Application of a Robotic Tele-Echography System for COVID-19 Pneumonia. J. Ultrasound Med. 2021, 40, 385-390. [CrossRef] 
116. Akbari, M.; Carriere, J.; Meyer, T.; Sloboda, R.; Husain, S.; Usmani, N.; Tavakoli, M. Robotic Ultrasound Scanning With Real-Time Image-Based Force Adjustment: Quick Response for Enabling Physical Distancing During the COVID-19 Pandemic. Front. Robot. AI 2021, 8, 62. [CrossRef]

117. Kallel, A.; Rekik, M.; Khemakhem, M. Hybrid-based Framework for COVID-19 Prediction via Federated Machine Learning Models. J. Supercomput. 2021. [CrossRef]

118. Nasser, N.; Emad-ul-Haq, Q.; Imran, M.; Ali, A.; Razzak, I.; Al-Helali, A. A smart healthcare framework for detection and monitoring of COVID-19 using IoT and cloud computing. Neural. Comput. Appl. 2021. (online ahead of print). [CrossRef] 